\title{
Flexural Strength Prediction of Welded Flange Plate Connections Based on Slenderness Ratios of Beam Elements Using ANN
}

\author{
Amir A. Hedayat $\mathbb{D}^{1,2}{ }^{1,2}$ Ehsan Jazebi, ${ }^{3}$ Saman AsadAbadi, ${ }^{4}$ and Amin Iranpour ${ }^{2,3}$ \\ ${ }^{1}$ Department of Civil Engineering, Islamic Azad University, Kerman Branch, Kerman, Iran \\ ${ }^{2}$ Pars Sustainable Seismic Structures Co., Kerman, Iran \\ ${ }^{3}$ Department of Civil Engineering, Shahid Bahonar University of Kerman, Kerman, Iran \\ ${ }^{4}$ Department of Civil Engineering, Rafsanjan Vali-e-Asr University, Rafsanjan, Iran \\ Correspondence should be addressed to Amir A. Hedayat; amirahmad1356@yahoo.com
}

Received 14 July 2017; Revised 10 November 2017; Accepted 3 December 2017; Published 29 March 2018

Academic Editor: Luigi Di Sarno

Copyright ( 2018 Amir A. Hedayat et al. This is an open access article distributed under the Creative Commons Attribution License, which permits unrestricted use, distribution, and reproduction in any medium, provided the original work is properly cited.

\begin{abstract}
The present study was aimed to investigate the strength and ductility of welded flange plate (WFP) connections. Using the FE method, 52 WFP connections with different beam overall depths and beam flanges/web slenderness ratios were analyzed. Fragility curves indicated that, for a WFP connection which is designed based on the seismic codes, its strength is of more concern than its ductility. In addition, limiting the width-to-thickness ratios of the beam flanges and web plates to $0.3 \sqrt{E / f_{y}}$ and $2.45 \sqrt{E / f_{y}}$, respectively, may not always lead to the achievement of adequate connection's strength and ductility. Proposed theoretical formulas and artificial neural network- (ANN-) based models developed in this study were able to adequately predict the connection strength.
\end{abstract}

\section{Introduction}

Steel moment-resisting frames had extensive brittle fractures in their welded connections during the Northridge (1994) and Kobe (1995) earthquakes [1]. Since then, modifications for design procedure of pre-Northridge connections have been introduced. E70T-4 type welding was changed to E70-TGK2 with smooth welding access holes and backing bars removed from the bottom beam flange [2-4]. This type of connection is now known as post-Northridge connection. Three methods are generally used to improve the strength and ductility of the post-Northridge connections: (a) strengthening the connection by adding additional elements; (b) reducing the beam section by cutting a portion of the beam flange [5] or the beam web [6-8]; and (c) adding slit dampers at the connection area as additional energy dissipation source [9].

Among strengthening methods, one of the most common methods to enhance the ductility of rigid connections was using plates (Figure 1). This connection is named by
FEMA350 [10] as welded flange plate (WFP) connection. In this connection, the applied moment and the shear force are transferred to the column flange through the top and the bottom flange plates and a shear plate (also known as shear tab), respectively. The rectangular-shaped top and bottom flange plates have the same width and length.

Whittaker and Gilani [11] tested three WFP connections. Specimens were composed of W21 and W24 beams and I-shaped columns of Grade 50 steel with two same size rectangular-shaped flange plates. They investigated the effect of contribution of the column panel zone (PZ) to the plastic rotation capacity of the joint. In these tests, the joint plastic rotation capacity varied between 0.028 and 0.045 radian. All specimens (except the specimen of weak PZ) experienced excessive strength degradation. SAC Joint Venture [12] tested five WFP connections. All specimens were fabricated from W30 $\times 99$ Grade 50 beams and Grade 50 rectangularor trapezoidal-shaped reinforcing plates. The key design variables were loading history, $\mathrm{PZ}$ strength and stiffness, and flange plate thickness and geometry. None of the five 


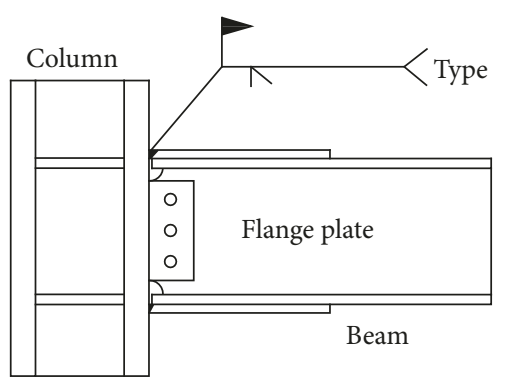

FIGURE 1: Typical welded flange plate (WFP) connection.

connections failed in a brittle manner, and the maximum beam plastic hinge rotations ranged between $2.3 \%$ and $3.9 \%$ radians. These specimens experienced excessive strength degradation at large rotations. In recent years, Ghobadi et al. [13] and Gholami et al. [14] tested few WFP connections. In these tests, the section used for beams was either IPE270 (beam depth $=270 \mathrm{~mm}$ ) or a built-up section with the overall depth equal to $380 \mathrm{~mm}$. These experimental tests indicated that WFP connections can reach to an acceptable level of strength and ductility.

With reference to the results summarized in the previous paragraph, it can be seen that using flange plates was effective to enhance the ductility of the pre-Northridge connections. However, it always was not the case for the connection strength. Experimental tests of the WFP connections indicated that some of these specimens experienced excessive strength degradation such that, at $4 \%$ total rotation, the measured flexural resistance of the connection determined at the column face $\left(M_{\mathrm{cf}}\right)$ was below the 80 percent of the plastic moment of the connected beam $\left(M_{\mathrm{pb}}\right)$. For instance, the $M_{\mathrm{cf}} / M_{\mathrm{pb}}$ ratios at four percent total rotation for specimens RC06 (beam section $=\mathrm{W} 30 \times 99$ ) and FUSD 1 (beam section $=\mathrm{W} 21 \times 50$ ) of [12] and [11] were 0.65 and 0.74 , respectively. While this parameter for specimens LF30 (beam depth $=380 \mathrm{~mm}$ ) and RC2 (beam section = IPE270; beam depth $=270 \mathrm{~mm}$ ) of [14] and [13] was 1.1 and 1.25 , respectively. Based on the seismic provision [15], from the strength point of view, a connection is acceptable if the ratio of $M_{\mathrm{cf}}$ and $M_{\mathrm{pb}}$ at $4 \%$ total rotation is greater than 0.8 . Hence, it might be concluded that, for a WFP connection which is even designed based on the seismic provisions, its strength is of concern rather than its ductility. The main differences between the sections used by these researchers were the beam overall depth and the slenderness ratios of the beam elements. In comparison to the sections used by Kim et al. [12], Gholami et al. [14], and Ghobadi et al. [13] used shallow beams of very compact flange and web. In other words, slenderness ratio of the beam elements can play a significant role to enhance the strength and ductility of the WFP connections. A detailed discussion about other effective parameters can be found in [16].

Artificial neural network (ANN) is a well-known branch of artificial intelligence. ANNs formulate a mathematical model for a system in which no clear relationship is available between inputs and outputs. In recent years, researchers have successfully employed the mathematical models developed on the basis of ANN to predict the behavior of structural elements in different applications [17-20].

At the moment, many of steel moment frames, especially in Iran, have been constructed using WFP connection. As a result, it seems that having a reliable mathematical model which is able to adequately predict the behavior of WFP connections can be useful for either detailing the connected beam for new buildings or detecting the weak connections in existing buildings. Hence, the main aim of the present study was to estimate the strength of the WFP connections based on the effective parameters. For this purpose, using the finite element method, numerous WFP connections of different beam overall depth and various beam flange and web slenderness ratios were created and analyzed. Then, using the results of FE analyses, new theoretical and ANN-based empirical formulas were proposed to predict the strength of the WFP connections.

\section{Finite Element Modeling}

In order to verify the accuracy of finite element modeling, specimens LF30 of [14] and RC06 of [12] were modeled using ANSYS software [21]. Specimen LF30 was composed of a shallow beam, a built-up I-380 $\times 200 \times 8 \times 12 \mathrm{~mm}$ beam, and a built-up B- $400 \times 400 \times 20 \times 20(\mathrm{~mm})$ box column. The bottom flange was a rectangular-shaped plate $250 \times 300 \times 15$ (length $=300 \mathrm{~mm}$; width $=250 \mathrm{~mm}$ ). The width of the top flange plate at the column face level was $200 \mathrm{~mm}$ and at the end of the flange plate was $170 \mathrm{~mm}$. The length and thickness of the top flange plate were $300 \mathrm{~mm}$ and $20 \mathrm{~mm}$, respectively. In this specimen, the steel grade used for both beam and column was ASTM A36. Specimen RC06 was composed of a W30 $\times 99$ beam and a W $14 \times 176$ column. For this specimen, the material used for both beam and column were made of A572 Grade 50 steel [12], and the length of the column and the beam were $3450 \mathrm{~mm}$ and $3400 \mathrm{~mm}$, respectively. The thickness of the continuity plates and the web doubler plate are $25 \mathrm{~mm}$ and $10 \mathrm{~mm}$, respectively. The high fracture toughness weld metal used was E70.

In finite element models, all connection's parts were modeled using shell elements (SHELL181 in ANSYS program). Interaction between plates (e.g., interaction between the flanges of beam and the top or the bottom flange plates) was modeled using contact elements. SHELL181 is a multilayer four-nodes shell element which has the ability to model plasticity, large deflection, and large strain phenomena. In this case, each element was separated into five layers across the thickness. The number of layers was selected based on the finite element study carried out by Gilton and Uang [22]. In order to determine the appropriate mesh density, a study on mesh sensitivity was carried out based on the recommendations given by ANSYS software. Results were then compared with the related experimental results of [12, 14].

To perform material nonlinearity analyses, plasticity behavior was based on the von Mises yielding criteria and the associated flow rule. Isotropic hardening was assumed for the monotonic analysis, whereas kinematic hardening was assumed for the cyclic analysis as used by Mao et al. [23] and Ricles et al. [24]. For base metals, both bilinear and 


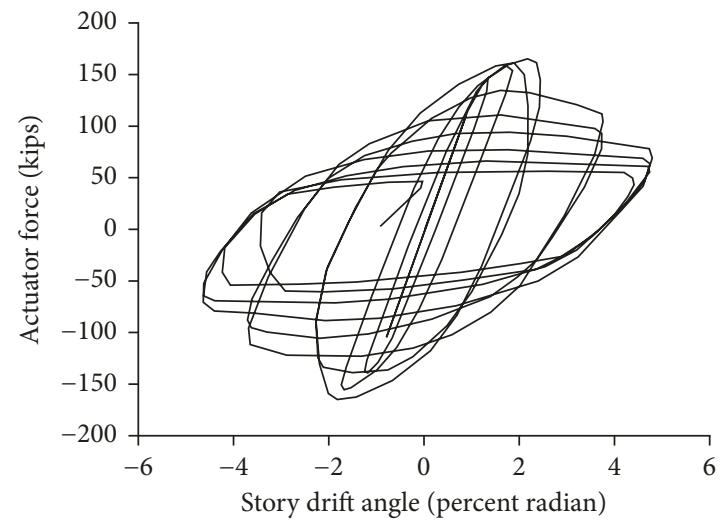

(a) Experimental test conducted by Kim et al. [12]

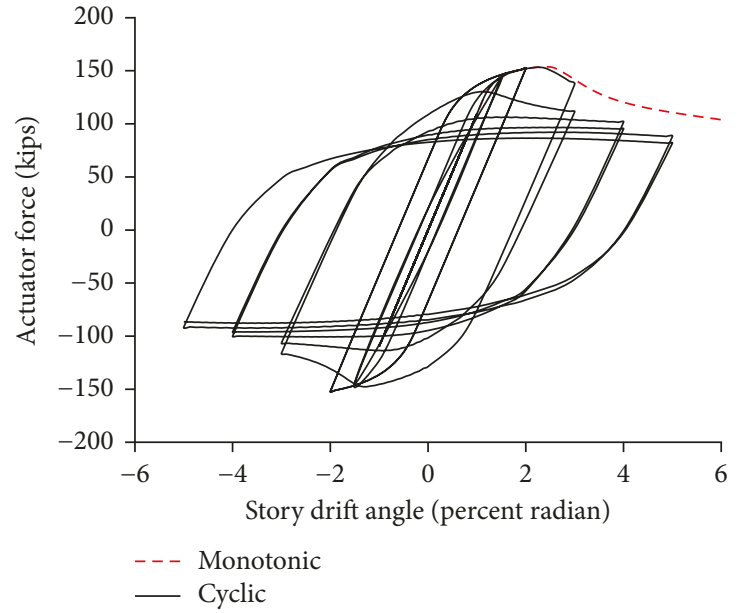

(b) Finite element model

FIgUre 2: Applied force-rotation curve of specimen RC06.

multilinear material responses were investigated. However, the analytical results showed that the use of multilinear response agreed well with the experimental results. For weld metals, a multilinear material response based on the material property given by Mao et al. [23] and Ricles et al. [24] was used.

Nonlinear geometric analyses were performed through a small strain, large displacement formulation. The monotonic analyses were conducted by applying a monotonic vertical displacement load to the beam tip until more than 4 percent total rotation at column web center was achieved and the load history recommended by the AISC [15] was utilized for cyclic analyses. When loads are applied only in the vertical direction, the out-of-plane deformations (normal to the web) may not occur. Therefore, in order to ensure that buckling would occur due to instability of model, the imperfect model was used. In order to determine the imperfect model, first the buckling mode shapes were computed in a separate buckling analysis and then were implemented to perturb the original perfect geometry of the model.

In order to verify the accuracy of the models, the experimental results of specimens RC06 and LF30 were compared to the analytical results obtained from the finite element models in terms of load-rotation and moment-rotation curves. Figures 2 and 3 show these comparisons for specimens RC06 and LF30, respectively. As Figures 2 and 3 show, the applied load-rotation and moment-rotation curves obtained from the finite element analyses are in good agreement with the experimental ones. Figure 4 also shows the plastic equivalent strain distribution for specimen RC06 at 5.5 percent total rotation. In Figure 4, high concentration of the plastic equivalent strain at the end of the flange plates of the beam is quite evident, and similar results were achieved during the experimental tests of Kim et al. [12]. Furthermore, as Figure 4(b) shows, for the finite element model, the beam flanges experienced a significant local buckling which is completely consistent with those that occurred during the experimental tests.

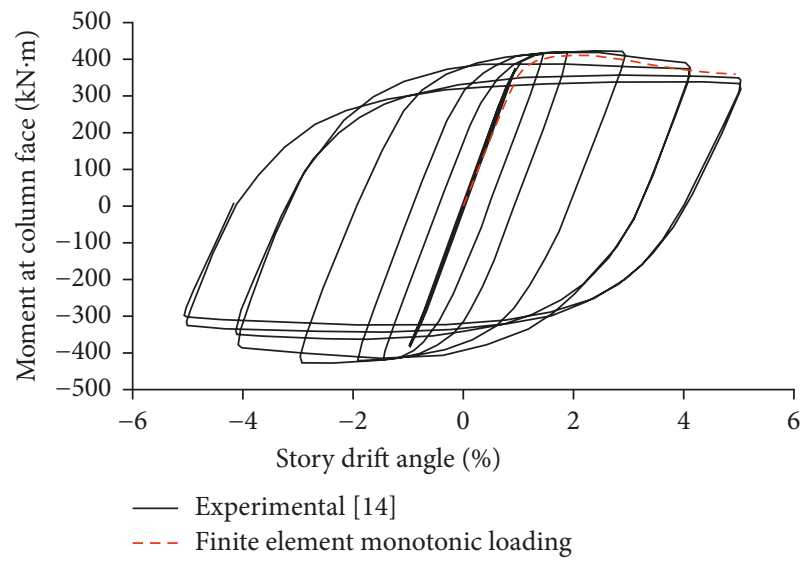

Figure 3: Comparison between experimental and analytical results of specimen LF30.

\section{Failure Criterion}

It should be noted that the fracture prediction is the most questionable part of a finite element study because it is inherently a complicated phenomenon and is dependent on many parameters such as weld and base metal properties, weld defects, notch effects, weld quality, and weld toughness. In this study, it was assumed that the qualified welders and fabricators are employed, and high fracture toughness weld metals are used (as these should be based on the AISC 360-10 [25], Specification for Structural Steel Buildings). Considering the fact that the locations of high level of strains have significant probability of premature fracture and by comparing the finite element results of specimens RC06 and LF30 with the experimental results presented by Kim et al. [12] and Gholami et al. [14], the following failure criterion was defined.

The connection fracture may occur when the von Mises strains at the whole width of either the beam flange (at the end of flange plate length) or the flange plates (at the column 


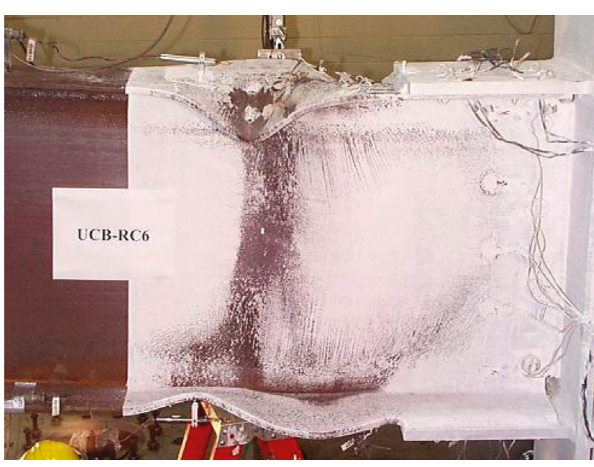

(a) Experimental test done by Kim et al. [12]

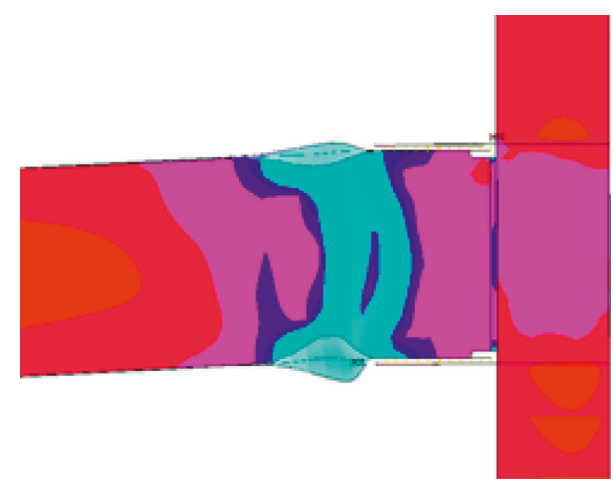

(b) Finite element model

FIgURE 4: Plastic equivalent strain distribution of specimen RC06.

face level) exceed the strain associated with the ultimate strength of the materials. A similar failure criterion was also used by other researchers [26]. Note that the connection failure can also be predicted using rupture index (RI) (e.g., $[27,28])$. This index is defined as the ratio between the plastic equivalent strain index and the ductile fracture strain. However, this method may be better when the fracture initiates from the beam web rather than the beam flange. Note that none of the mentioned methods are intended to predict exact rotation capacities for connections; rather, they provide a tool for comparing various models.

\section{Sections Used to Design WFP Connections}

Proposed design procedures to modify pre- and postNorthridge connections are usually based on three beam sections: W $36 \times 150, \mathrm{~W} 30 \times 99$, and $\mathrm{W} 24 \times 68$. Therefore, all parametric studies were done on specimens SPE07 (beam: W36 $\times 150$; column: W14 $\times 257$ ), SPE05 (beam: W30 $\times 99$; column: W14 $\times 176$ ), and SPE03 (beam: W24 $\times 68$; column: $\mathrm{W} 14 \times 120$ ). These specimen sizes were chosen since they may be good representatives of the conventional pre/post Northridge specimen sizes, large, medium, and small [3] and were also tested in phase 1 of SAC steel projects [29]. The beam and column lengths of these specimens were similar to those that were used for specimen RC06. In addition to these specimens, specimen SPE01 which is similar to the specimen LF30 of [14] was also used. This specimen was composed of a built-up I- $380 \times 200 \times 8 \times 12(\mathrm{~mm})$ beam and a built-up box column $(B-400 \times 400 \times 20 \times 20 \mathrm{~mm})$. This specimen was used so that we could have a wider range of the beam depths, from a very deep beam $($ W $36 \times 150)$ to a very shallow beam $(I-380 \times 200 \times 8 \times 12)$.

All WFP connections were designed based on the AISC $[15,25]$. To design the flange plates, the maximum applied moment at the column face $\left(\mathrm{M}_{\mathrm{cf}}\right)$ was determined using (1). In this equation, $Z_{b}$ and $f_{\mathrm{ye}}$ are the beam plastic section modulus and the expected yield stress of the material, respectively. $S_{c}$ is equal to the length of the flange plate plus $1 / 4$ of the beam overall depth, and $V_{\exp }$ is the expected shear force at the plastic hinge location. $C_{\mathrm{pr}}$ is a factor to account for the peak connection strength, including strain hardening, local restraint, and additional reinforcement.
In FEMA350 [10], the $C_{\mathrm{pr}}$ factor is given by equation $\left(f_{y}+f_{u}\right) / 2 f_{y}$, where $f_{u}$ is the specified minimum tensile stress of the material. FEMA350 [10] proposes the use of value 1.2 for any case of modified connections except where otherwise noted in the individual connection design procedures. In the present study, the $C_{\mathrm{pr}}$ factor used to design the WFP connections was 1.1 which is as same as the one that was used by Kim et al. [12].

$$
M_{\mathrm{cf}}=C_{\mathrm{pr}} \cdot Z_{b} \cdot f_{\mathrm{ye}}+V_{\mathrm{exp}} \cdot S_{c} .
$$

\section{Finite Element Models and Results}

In general, in WFP connections, the thickness of the flange plates is larger than those of the beam flanges. This subject is much more pronounced when the flange plates are designed based on the seismic provision (i.e., (1) is used to detail the flange plates). In this case, an elastic region with a length equal to the length of the flange plates forms at the beginning of the beam length. It therefore causes the majority of nonlinear deformations to be concentrated at the plastic hinge area which is the beam flanges and web plates located after the tip of the flange plates (Figure 4). In this case, the behavior of a WFP connection is mainly controlled by the slenderness of the beam elements and further strengthening of the connection area by adding additional elements such as rib plates may not be effective. Here, when the beam elements are slender, an excessive local buckling will occur in the beam flange and web plates, and consequently significant strength degradation can be expected. On the other hand, when the beam elements are too compact, the beam elements will not experience any controlled local buckling. In this case, the main energy dissipation source (i.e., beam end) will be lost, and consequently the majority of stresses and strains concentrate at the column face level. This finally can lead to the premature fracture of the connection and to the excessive reduction in the connection's strength and ductility. Hence, by controlling the local buckling of the beam flange and web plates, higher connection strength and ductility can be expected.

The beam flange and web local buckling can be controlled by limiting the width-to-thickness ratios of these 
elements. These ratios for the beam flange and web can be expressed by equations $b / t=b_{\mathrm{fb}} /\left(2 \cdot t_{\mathrm{fb}}\right)$ and $h / t=\left(d_{b}-2 k\right) / t_{\mathrm{wb}}$, respectively. In these equations, $b_{\mathrm{fb}}, t_{\mathrm{fb}}, t_{\mathrm{wb}}, d_{b}$, and $k$ are the beam flange width, the beam flange thickness, the beam web thickness, the beam overall depth, and the distance from the outer face of the beam flange to the web toe of the fillet, respectively. Based on the seismic provision for structural steel buildings [15], the width-to-thickness ratios of the flange and web of a beam used in a special moment frame, must be limited to $0.3 \sqrt{E_{s} / f_{y}}$ and $2.45 \sqrt{E_{s} / f_{y}}$, respectively, where $E_{s}$ and $f_{y}$ are the modulus of elasticity and the yield stress of the material, respectively. In order to realize the effect of the parameters $b / t$ and $h / t$ on the strength and ductility of the WFP specimens, these ratios were defined as a function of $\sqrt{E_{s} / f_{y}}$ (2). Hence, based on the AISC [15] and using these definitions, the values of parameters $\alpha_{f}$ and $\alpha_{w}$ for a beam used in a special moment frame must be at most equal to 0.3 and 2.45 , respectively.

$$
\begin{aligned}
& \frac{b}{t}=\alpha_{f} \sqrt{\frac{E_{s}}{f_{y}}} \longrightarrow \alpha_{f}=\frac{(b / t)}{\sqrt{E_{s} / f_{y}}}, \\
& \frac{h}{t}=\alpha_{w} \sqrt{\frac{E_{s}}{f_{y}}} \longrightarrow \alpha_{w}=\frac{(h / t)}{\sqrt{E_{s} / f_{y}}} .
\end{aligned}
$$

Table 1 summarizes the effects of different values used for parameters $\alpha_{f}, \alpha_{w}$, and $L_{b} / d_{b}$ on the strength and ductility of WFP specimens SPE07, SPE05, SPE03, and SPE01. In Table $1, L_{b}$ is the beam length measured between the faces of the two adjacent columns. $M_{\mathrm{cf}} / M_{\mathrm{pb}}$ is the normalized connection strength at four percent total rotation under cyclic loading and $\theta$ is the total rotation of the connection at the failure time. Figure 5 graphically compares the effect of parameters $\alpha_{f}, \alpha_{w}$, and $L_{b} / d_{b}$ on the strength of some of WFP specimens SPE07, SPE05, SPE03, and SPE01. Figure 5 was drawn as such that, in each case, one parameter which was considered as the main parameter varied in its total range, while the other two parameters were kept constant or varied in a limited range. As Figure 5 shows, by reducing the values of parameters $\alpha_{f}$ and $\alpha_{w}$ and increasing the value of parameter $L_{b} / d_{b}$ the connection strength increased. However, as the results of Table 1 indicate, the high value of strength is not always accompanied by the high value of ductility such that excessive decrease in the value of parameters $\alpha_{f}$ and $\alpha_{w}$ was detrimental and caused a significant reduction in the connection ductility. These connections generally failed due to the fracture of flange plates at the column face level. Based on the FE results of this study and available experimental results of other researchers, following questions might be answered. However, more accurate answers need more numerical and experimental analyses.

5.1. First Question. How reliable is a WFP connection? This question should be answered from both strength and ductility points of view. From ductility point of view, a connection is reliable if it is able to accommodate a story drift angle of at least $0.04 \mathrm{rad}$ [15]. Using the available test results, FEMA355D [30] has presented related relationships to predict the connection plastic rotational capacity in terms of the connection type and the overall depth of the connected beam. In this reference, using the experimental results of only 5 specimens tested by Kim et al. [12], the rotational capacity of the WFP connections has been estimated using the regression analysis. The recommended rotation limit presented by this reference is 3\% plastic rotation (or $4 \%$ total rotation, assuming the elastic rotation is $1 \%$ ). This means that, from ductility point of view, this connection is one hundred percent reliable. However, this question might be more accurately answered using the fragility curves. Here, finite element and experimental results presented in Table 1 were used to find the cumulative distribution function (CDF) also known as fragility functions for the normalized strength $\left(M_{\mathrm{cf}} / M_{\mathrm{pb}}\right)$ and ductility $(\theta)$ of WFP connections. Fragility curves were obtained by assuming that the data has lognormal distribution. It has been reported by many of researchers [31-33] that the lognormal distribution provides relatively good fit to empirical cumulative distributions computed from experimental or numerical data. As the fragility curves shown in Figures 6(a) and 6(b) indicate, the probabilities of achieving adequate strength $\left(M_{\mathrm{cf}} / M_{\mathrm{pb}} \geq 0.8\right)$ and ductility $(\theta \geq 4 \%)$ for WFP connections are $49 \%$ and $92 \%$, respectively. This might be the reason of why this connection type has not been prequalified by the AISC358-10 [34]. These results also indicate that, for a WFP connection, its strength is of more concern rather than its ductility.

5.2. Second Question. Are 0.3 and 2.45 the appropriate values for parameters $\alpha_{f}$ and $\alpha_{w}$, respectively, to achieve both adequate connection's strength and ductility simultaneously when WFP connection is used in a special moment frame? This question can be answered by comparing the results of specimen numbers 9, 30, 43, and 52 presented in Table 1. As the results show, only specimen number 52 in which the beam depth is equal to $380 \mathrm{~mm}$ could achieve adequate connection strength (i.e., $M_{\mathrm{cf}} / M_{\mathrm{pb}} \geq 0.8$ ). In other words, the limiting values for parameters $\alpha_{f}$ and $\alpha_{w}$ (i.e., 0.3 and 2.45, resp.) must be modified for beams deeper than $400 \mathrm{~mm}$. Similar conclusion might be drawn by investigating the experimental results of specimens RC06 and FUSD-1 tested by Kim et al. [12] and Whittaker and Gilani [11], respectively. Specimen FUSD-1 was composed of $\mathrm{W} 21 \times 50$ beam $\left(\alpha_{f}=0.27\right.$ and $\left.\alpha_{w}=2.10\right)$. The value of $M_{\mathrm{cf}} / M_{\mathrm{pb}}$ at four percent total rotation for this connection was 0.74 . Based on the result obtained from specimen $\mathrm{RC06}\left(M_{\mathrm{cf}} / M_{\mathrm{pb}}=0.65\right.$, $\alpha_{f}=0.33$ and $\alpha_{w}=2.21$, Kim et al. [12] recommended a reduction in the maximum width-to-thickness ratio of the beam web from $520 / \sqrt{f_{y}}$ to $350 / \sqrt{f_{y}}\left(f_{y}\right.$ is yield stress in $\mathrm{ksi}$ ), where the latter is corresponded to $\alpha_{w}$ equal to 2.05 .

5.3. Third Question. What can be the maximum values for parameters $\alpha_{f}$ and $\alpha_{w}$ to achieve the minimum required connection's strength and ductility requested by AISC [15]? Based on the results presented in Table 1, it can be concluded that 0.3 and 2.2 are the maximum permissible values for parameters $\alpha_{f}$ and $\alpha_{w}$, respectively, when the beam depth is less than $800 \mathrm{~mm}$. 
TABLE 1: Effect of parameters $\alpha_{f}$ and $\alpha_{w}$ on the connection's strength and ductility.

\begin{tabular}{|c|c|c|c|c|c|c|c|c|c|c|}
\hline Specimen & Number & $t_{f}(\mathrm{~mm})$ & $t_{w}(\mathrm{~mm})$ & $L_{b} / 2(\mathrm{~mm})$ & $d_{b}(\mathrm{~mm})$ & $\alpha_{f}$ & $\alpha_{w}$ & $L_{b} / d_{b}$ & $M / M_{P}$ at $4 \%$ total rotation & $\theta(\%)$ \\
\hline \multirow{15}{*}{ SPE05 } & 1 & 18.00 & 13.21 & 3400 & 750 & 0.32 & 2.21 & 9.07 & 0.80 & 5.90 \\
\hline & 2 & 19.00 & 13.21 & 3400 & 750 & 0.30 & 2.21 & 9.07 & 0.80 & 6.00 \\
\hline & 3 & 20.00 & 13.21 & 3400 & 750 & 0.28 & 2.21 & 9.07 & $\mathrm{NA}^{*}$ & 2.70 \\
\hline & 4 & 17.02 & 14.00 & 3400 & 750 & 0.33 & 2.09 & 9.07 & 0.81 & 5.70 \\
\hline & 5 & 17.02 & 14.60 & 3400 & 750 & 0.33 & 2.00 & 9.07 & 0.82 & 6.00 \\
\hline & 6 & 17.02 & 15.00 & 3400 & 750 & 0.33 & 1.95 & 9.07 & 0.85 & 6.00 \\
\hline & 7 & 17.02 & 15.50 & 3400 & 750 & 0.33 & 1.89 & 9.07 & 0.89 & 6.00 \\
\hline & 8 & 17.02 & 16.00 & 3400 & 750 & 0.33 & 1.77 & 9.07 & 0.78 & 4.80 \\
\hline & 9 & 19.00 & 12.00 & 3400 & 750 & 0.30 & 2.45 & 9.07 & 0.78 & 4.00 \\
\hline & 10 & 19.00 & 13.21 & 3400 & 750 & 0.30 & 2.21 & 9.07 & 0.80 & 6.00 \\
\hline & 11 & 19.00 & 14.00 & 3400 & 750 & 0.30 & 2.09 & 9.07 & 0.90 & 6.00 \\
\hline & 12 & 19.00 & 14.60 & 3400 & 750 & 0.30 & 2.00 & 9.07 & 0.90 & 6.00 \\
\hline & 13 & 19.00 & 15.00 & 3400 & 750 & 0.30 & 1.95 & 9.07 & 0.90 & 6.00 \\
\hline & 14 & 19.00 & 15.50 & 3400 & 750 & 0.30 & 1.89 & 9.07 & 0.89 & 6.00 \\
\hline & 15 & 19.00 & 16.50 & 3400 & 750 & 0.30 & 1.77 & 9.07 & 0.88 & 6.00 \\
\hline \multirow{16}{*}{ SPE03 } & 16 & 14.90 & 10.54 & 3400 & 600 & 0.33 & 2.17 & 11.33 & 0.79 & 4.92 \\
\hline & 17 & 15.50 & 10.54 & 3400 & 600 & 0.31 & 2.17 & 11.33 & 0.83 & 5.00 \\
\hline & 18 & 16.20 & 10.54 & 3400 & 600 & 0.30 & 2.17 & 11.33 & 0.86 & 5.08 \\
\hline & 19 & 17.20 & 10.54 & 3400 & 600 & 0.28 & 2.17 & 11.33 & 0.88 & 5.31 \\
\hline & 20 & 14.90 & 10.54 & 3400 & 600 & 0.33 & 2.17 & 11.33 & 0.79 & 4.92 \\
\hline & 21 & 14.90 & 10.90 & 3400 & 600 & 0.33 & 2.10 & 11.33 & 0.84 & 5.06 \\
\hline & 22 & 14.90 & 11.45 & 3400 & 600 & 0.33 & 2.00 & 11.33 & 0.86 & 5.15 \\
\hline & 23 & 14.90 & 11.75 & 3400 & 600 & 0.33 & 1.95 & 11.33 & 0.88 & 5.23 \\
\hline & 24 & 14.90 & 12.10 & 3400 & 600 & 0.33 & 1.90 & 11.33 & 0.89 & 5.31 \\
\hline & 25 & 14.90 & 13.15 & 3400 & 600 & 0.33 & 1.75 & 11.33 & 0.89 & 4.77 \\
\hline & 26 & 16.20 & 10.85 & 3400 & 600 & 0.30 & 2.12 & 11.33 & 0.87 & 5.23 \\
\hline & 27 & 16.20 & 11.45 & 3400 & 600 & 0.30 & 2.00 & 11.33 & 0.89 & 5.38 \\
\hline & 28 & 16.20 & 11.77 & 3400 & 600 & 0.30 & 1.95 & 11.33 & 0.89 & 5.54 \\
\hline & 29 & 16.20 & 12.10 & 3400 & 600 & 0.30 & 1.90 & 11.33 & 0.89 & 5.69 \\
\hline & 30 & 16.20 & 9.35 & 3400 & 600 & 0.30 & 2.45 & 11.33 & 0.78 & 5.08 \\
\hline & 31 & 16.20 & 13.20 & 3400 & 600 & 0.30 & 1.75 & 11.33 & $\mathrm{NA}^{*}$ & 2.54 \\
\hline \multirow{12}{*}{ SPE07 } & 32 & 23.80 & 15.88 & 3400 & 912 & 0.27 & 2.20 & 7.46 & 0.81 & 5.46 \\
\hline & 33 & 26.00 & 15.88 & 3400 & 912 & 0.25 & 2.20 & 7.46 & $\mathrm{NA}^{*}$ & 2.40 \\
\hline & 34 & 23.80 & 15.88 & 3400 & 912 & 0.27 & 2.20 & 7.46 & 0.81 & 5.46 \\
\hline & 35 & 23.80 & 17.50 & 3400 & 912 & 0.27 & 2.00 & 7.46 & 0.85 & 5.54 \\
\hline & 36 & 23.80 & 17.90 & 3400 & 912 & 0.27 & 1.95 & 7.46 & 0.87 & 5.62 \\
\hline & 37 & 23.80 & 18.40 & 3400 & 912 & 0.27 & 1.90 & 7.46 & 0.89 & 5.92 \\
\hline & 38 & 23.80 & 20.00 & 3400 & 912 & 0.27 & 1.75 & 7.46 & NA & 3.46 \\
\hline & 39 & 20.00 & 18.50 & 3400 & 912 & 0.33 & 1.90 & 7.46 & 0.72 & 4.60 \\
\hline & 40 & 21.70 & 18.50 & 3400 & 912 & 0.30 & 1.90 & 7.46 & 0.83 & 5.69 \\
\hline & 41 & 21.70 & 17.50 & 3400 & 912 & 0.30 & 2.00 & 7.46 & 0.77 & 4.77 \\
\hline & 42 & 21.70 & 15.88 & 3400 & 912 & 0.30 & 2.20 & 7.46 & 0.72 & 4.38 \\
\hline & 43 & 21.70 & 14.30 & 3400 & 912 & 0.30 & 2.45 & 7.46 & 0.69 & 4.23 \\
\hline \multirow{9}{*}{ SPE01 } & 44 & 13.00 & 8.00 & 2500 & 380 & 0.30 & 1.75 & 18.52 & 1.16 & 6.00 \\
\hline & 45 & 12.00 & 7.36 & 2500 & 380 & 0.32 & 1.90 & 18.52 & 1.08 & 4.77 \\
\hline & 46 & 12.00 & 7.00 & 2500 & 380 & 0.32 & 2.00 & 18.52 & 1.07 & 4.70 \\
\hline & 47 & 12.00 & 6.80 & 2500 & 380 & 0.32 & 2.06 & 18.52 & 1.07 & 4.60 \\
\hline & 48 & 12.00 & 6.30 & 2500 & 380 & 0.32 & 2.22 & 18.52 & 1.01 & 4.50 \\
\hline & 49 & 13.00 & 7.40 & 2500 & 380 & 0.30 & 1.89 & 18.52 & 1.14 & 6.00 \\
\hline & 50 & 13.00 & 7.00 & 2500 & 380 & 0.30 & 2.00 & 18.52 & 1.13 & 6.00 \\
\hline & 51 & 13.00 & 6.30 & 2500 & 380 & 0.30 & 2.22 & 18.52 & 1.08 & 6.00 \\
\hline & 52 & 13.00 & 5.75 & 2500 & 380 & 0.30 & 2.45 & 18.52 & 1.07 & 5.20 \\
\hline FUSD-1 [11] & 53 & 13.59 & 9.65 & 3000 & 529 & 0.27 & 2.10 & 11.34 & 0.74 & 4.30 \\
\hline RC06 [12] & 54 & 17.02 & 13.21 & 3400 & 750 & 0.33 & 2.21 & 9.07 & 0.65 & 4.50 \\
\hline $\mathrm{RC} 07$ [12] & 55 & 17.02 & 13.21 & 3400 & 750 & 0.33 & 2.21 & 9.07 & 0.80 & 5.50 \\
\hline RC08 [12] & 56 & 17.02 & 13.21 & 3400 & 750 & 0.33 & 2.21 & 9.07 & 0.69 & 5.50 \\
\hline RC2 [13] & 57 & 10.20 & 6.60 & 2500 & 270 & 0.27 & 1.36 & 18.52 & 1.25 & 4.00 \\
\hline RC4 [13] & 58 & 10.20 & 6.60 & 2500 & 270 & 0.27 & 1.36 & 18.52 & 1.25 & 6.00 \\
\hline LF30 [14] & 59 & 12.00 & 8.00 & 2500 & 380 & 0.32 & 1.75 & 13.16 & 1.10 & 5.00 \\
\hline LF50 [14] & 60 & 12.00 & 8.00 & 2500 & 380 & 0.32 & 1.75 & 13.16 & 1.07 & 5.00 \\
\hline
\end{tabular}




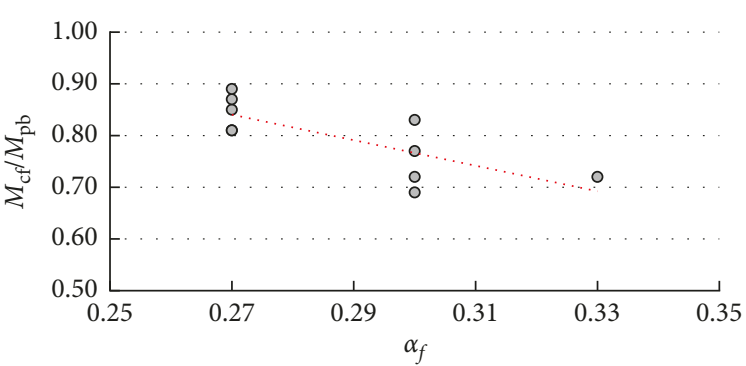

$\circ L_{b} / d_{b}=7.46 \& \alpha_{w}=1.9-2.45$

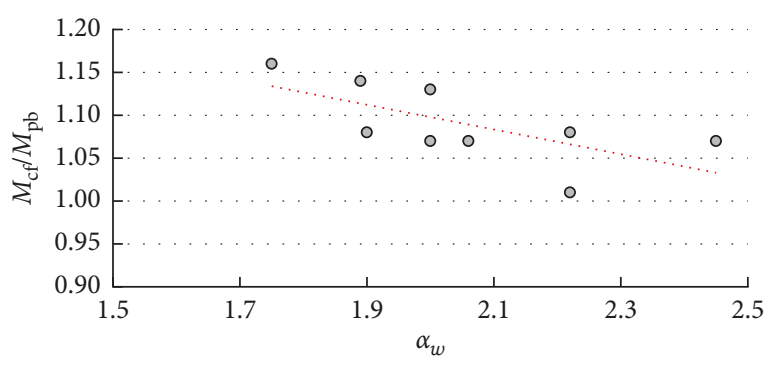

- $L_{b} / d_{b}=18.52 \& \alpha_{f}=0.3-0.32$

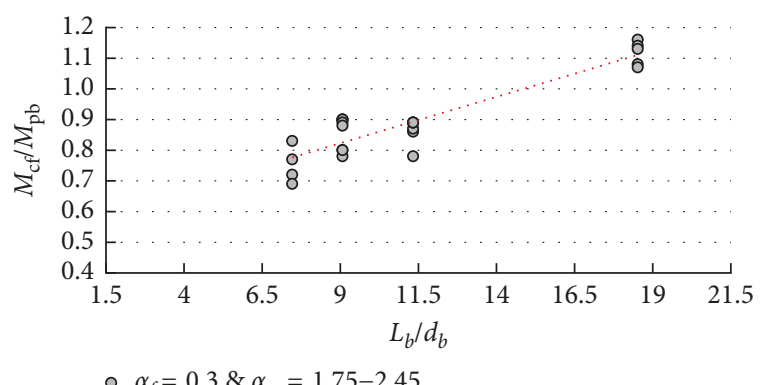

Figure 5: Effect of parameters $\alpha_{f}, \alpha_{w}$, and $L_{b} / d_{b}$ on the connection strength.

While for deeper beams, 0.275 and 2.2 might be the maximum appropriate values for parameters $\alpha_{f}$ and $\alpha_{w}$, respectively.

5.4. Forth Question. What can be the best values for parameters $\alpha_{f}$ and $\alpha_{w}$ to achieve the highest connection performance? By comparing the results presented in Table 1, it might be concluded that 0.3 and 1.9 are the best values for parameters $\alpha_{f}$ and $\alpha_{w}$, respectively, if the beam depth is less than $800 \mathrm{~mm}$. While for deeper beams, 0.275 and 1.9 might be the most suitable values for parameters $\alpha_{f}$ and $\alpha_{w}$, respectively.

5.5. Fifth Question. How can we estimate the strength of a WFP connection based on parameters $\alpha_{f} \alpha_{w}$, and $L_{b} / d_{b}$ ? In this study, in order to predict the strength of a WFP connection two types of mathematical formulas are proposed. First type is based on the theoretical formulations relevant to the flexural strength of beams with noncompact elements which is discussed here. The second type is on the basis of the artificial neural network-based models which is discussed in Section 6.3.

FE results indicated that the behavior of a WFP connection which is designed based on the seismic codes (i.e., (1)

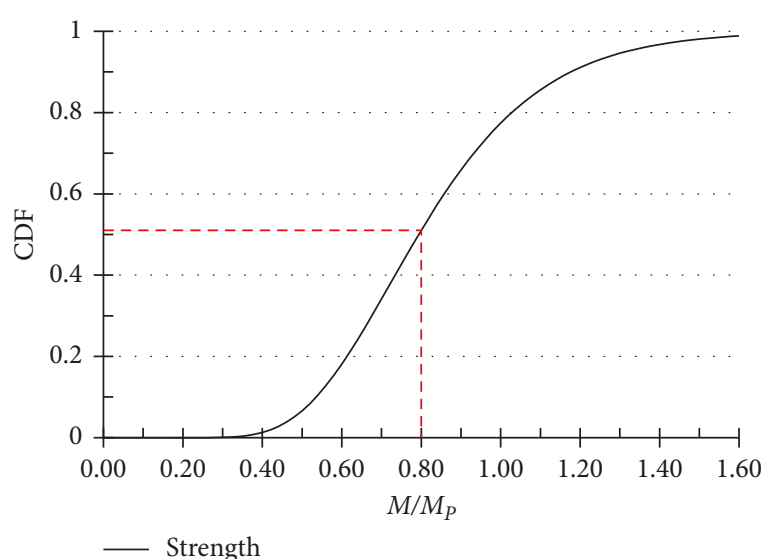

(a) Normalized strength

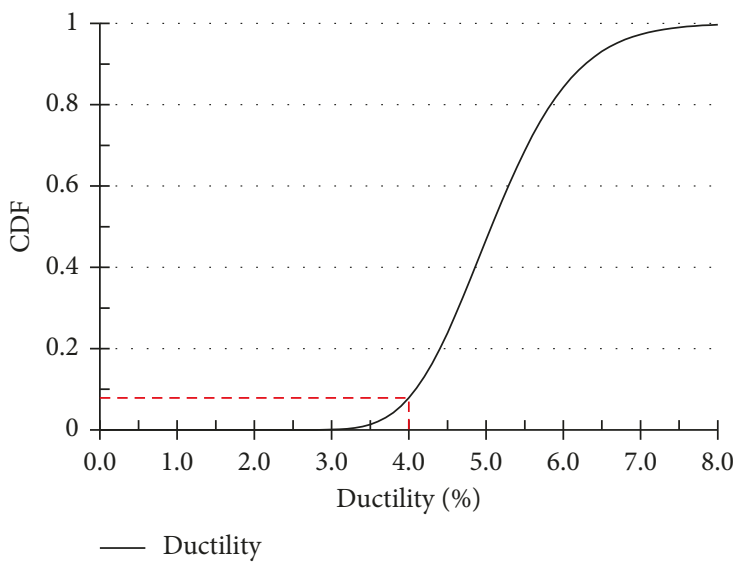

(b) Ductility of WFP connections

FIgURE 6: Cumulative distribution functions.

is used to detail the flange plates) is mainly controlled by the slenderness of the beam elements. Hence, it seems that equation F4-13 of AISC 360-10 [25] which is relevant to the flexural strength of beams with noncompact elements can be used to estimate the amount of strength reduction of a WFP connection at four percent total rotation when its beam undergoes flange and web local buckling. By using this equation and with respect to the answer of question 4 and assuming that the ratio of elastic to plastic section modulus of a beam section $\left(S_{b} / Z_{b}\right)$ is 0.87 , the normalized strength of a WFP connection at $4 \%$ total rotation $\left(M / M_{P}\right)$ can be estimated using (4)-(6). Note that these equations were derived by changing (1) the value of parameter $\lambda_{\mathrm{pf}}$ (limiting slenderness parameter for compact flanges) from $0.38 \sqrt{E / f_{y}}$ to $0.3 \sqrt{E / f_{y}}$ for beam depth less than or equal to $800 \mathrm{~mm}$; (2) the value of parameter $\lambda_{\mathrm{pf}}$ from $0.38 \sqrt{E / f_{y}}$ to $0.275 \sqrt{E / f_{y}}$ for beam depth greater than $800 \mathrm{~mm}$; (3) the value of parameter $\lambda_{\mathrm{pw}}$ (limiting slenderness parameter for compact web) from $3.76 \sqrt{E / f_{y}}$ to $1.9 \sqrt{E / f_{y}}$;

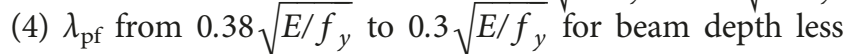
than or equal to $800 \mathrm{~mm}$; (5) the value of parameter $\lambda_{\text {rf }}$ 


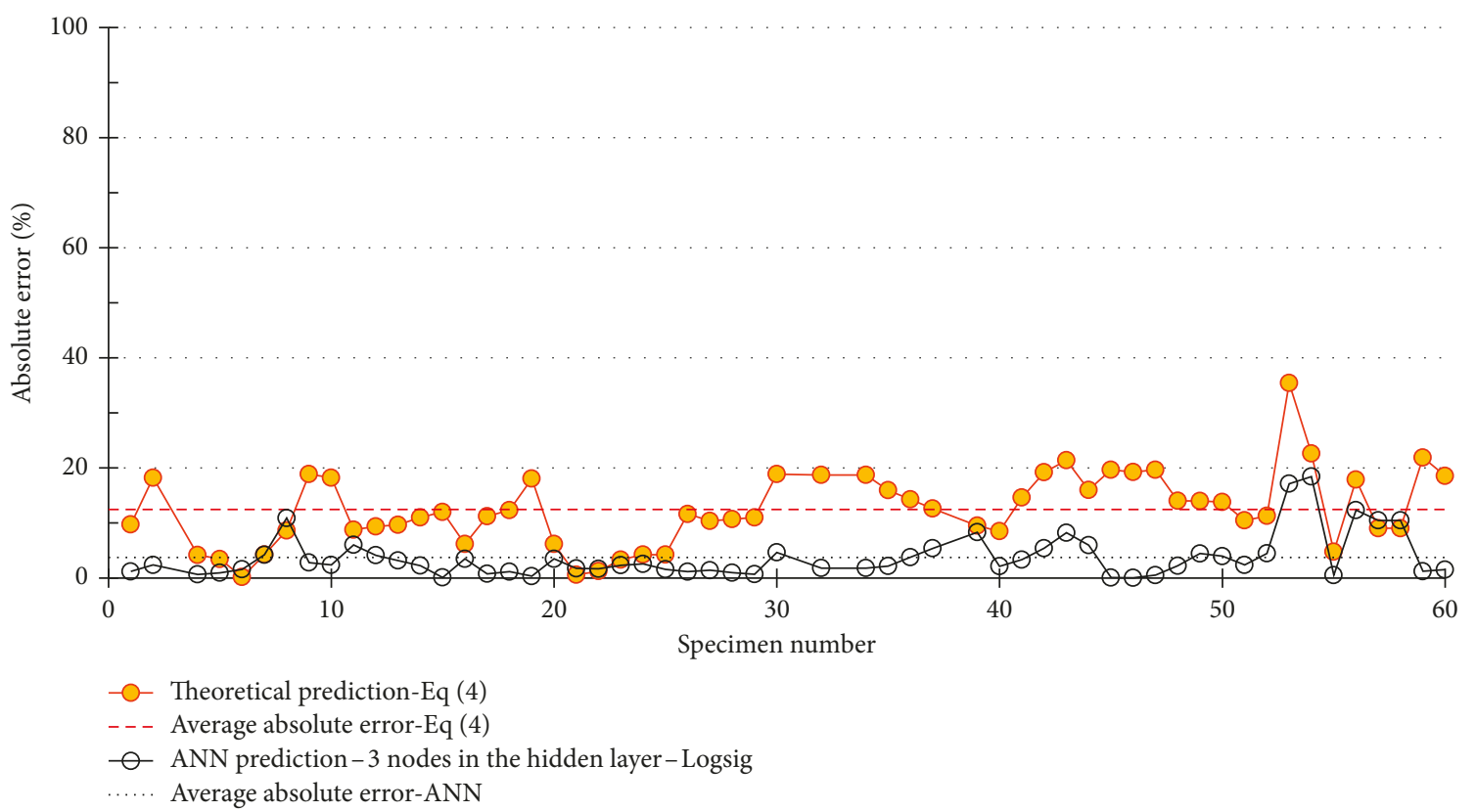

Figure 7: Comparison between proposed theoretical and ANN-based equations.

(limiting slenderness parameter for noncompact flange) from $1 \sqrt{E / f_{y}}$ to $0.38 \sqrt{E / f_{y}}$; and (6) the value of parameter $\lambda_{\mathrm{rw}}$ (limiting slenderness parameter for noncompact web) from $5.7 \sqrt{E / f_{y}}$ to $3.76 \sqrt{E / f_{y}}$. These changes were made mainly based on the answer of question 4 . In order to investigate the accuracy of (4), for all specimens presented in Table 1, the value of $M / M_{P}$ was calculated using this equation and then results were compared to the related experimental and numerical results. Figure 7 compares the related absolute errors for these specimens. As Figure 7 indicates, the proposed equation was able to adequately predict the connection strength with an acceptable level of error. The average of absolute error was $12.5 \%$.

$$
\begin{aligned}
\left(\frac{M}{M_{P}}\right) & = \begin{cases}1-0.39 \gamma_{f} & \text { for } \alpha_{w} \leq 1.9 \\
1-0.13\left(\gamma_{w}+3 \gamma_{f}-\gamma_{w} \gamma_{f}\right) & \text { for } \alpha_{w}>1.9\end{cases} \\
\gamma_{f} & =\frac{\alpha_{f}-\alpha_{\mathrm{fp}}^{\mathrm{pr}}}{0.38-\alpha_{\mathrm{fp}}^{\mathrm{pr}}} \\
\alpha_{\mathrm{fp}}^{\mathrm{pr}} & = \begin{cases}0.3 & \text { for beam depth } \leq 800 \mathrm{~mm} \\
0.275 & \text { for beam depth }>800 \mathrm{~mm}\end{cases} \\
\gamma_{w} & =\frac{\alpha_{w}-\alpha_{\mathrm{wp}}^{\mathrm{pr}}}{3.76-\alpha_{\mathrm{wp}}^{\mathrm{pr}}} \\
\alpha_{\mathrm{wp}}^{\mathrm{pr}} & =1.9 .
\end{aligned}
$$

5.6. Sixth Question. In order to reach adequate connection's strength, which one of the parameters $\alpha_{f}, \alpha_{w}$, and $L_{b} / d_{b}$ can

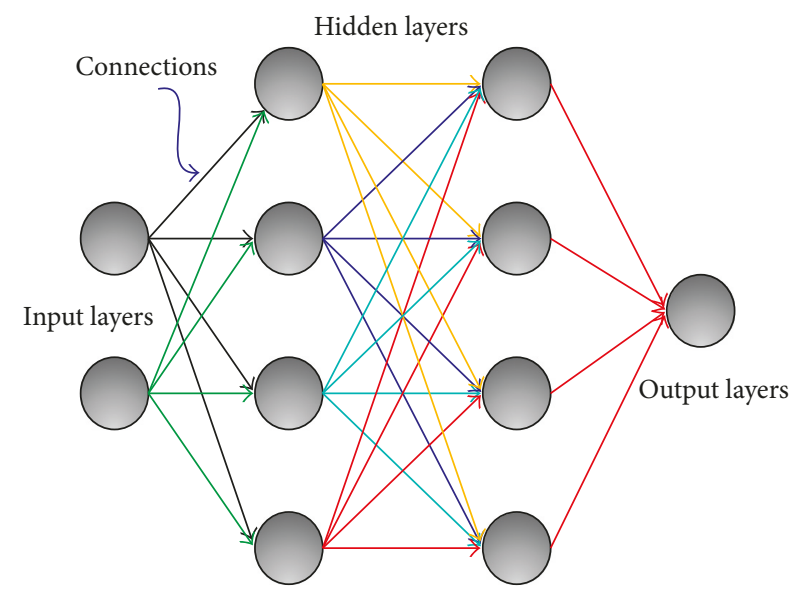

FIgURE 8: Structure of a typical ANN.

affect the result more? This question and also the previous question might be adequately answered using the ANNs which are discussed in the following section.

\section{Artificial Neural Network (ANN)}

ANN is inspired in natural nervous systems. A natural nervous system is composed of several natural neurons (or nodes) where they receive signals through synapses (or connections) and process them to obtain an output. As Figure 8 shows, an ANN is composed of three layers: one input layer, one output layer, and several hidden layers. Layers are made up of a number of interconnected "nodes" which contain an "activation function." Hence, nodes can be seen as computational units, and connections determine the information flow between nodes. Patterns are presented to the network via the "input layer," which communicates to one or more "hidden layers" 


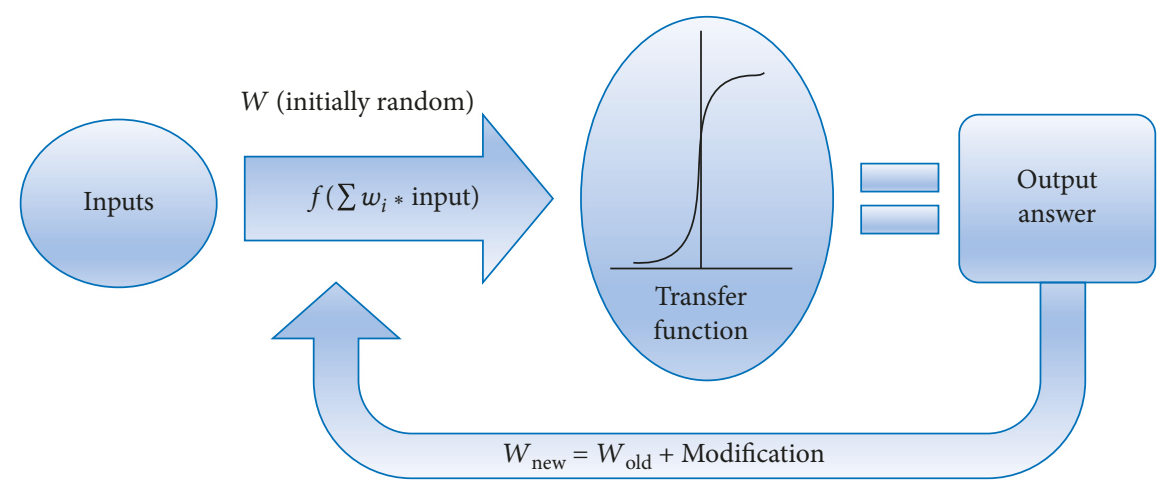

Figure 9: Backpropagation (BP) algorithm [36].
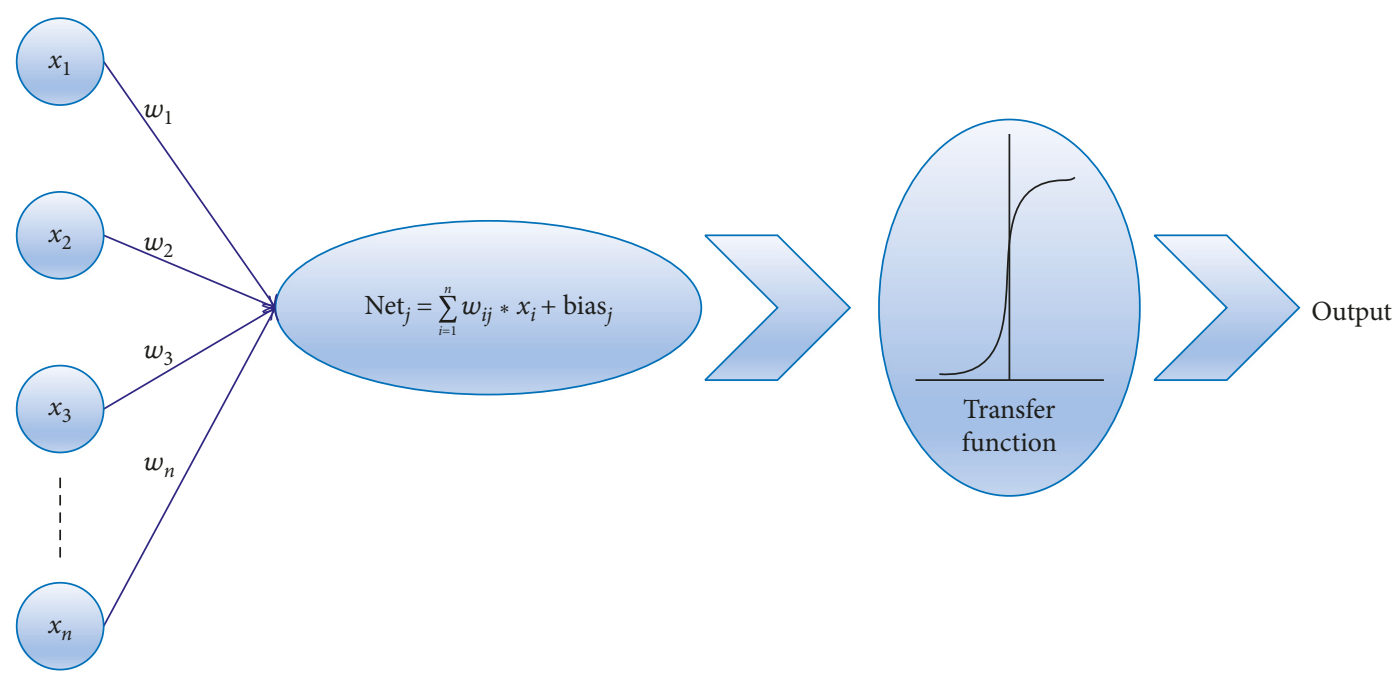

Figure 10: Simple artificial neural model.

where the actual processing is done via a system of weighted "connections." The higher a weight of a node is, the stronger the input. The hidden layers then link to an "output layer" where the answer is output as shown in Figure 8. The number of nodes in the input layer is equal to the number of independent variables which are believed to have an effect on the response of the network. The number of nodes in the output layer is associated to the number of dependent variables (i.e., outputs) which the network is going to predict them. There is no specific role to determine the number of nodes in the hidden layers. In fact, they can be determined by a try and error method to achieve the highest performance of the network which corresponds to the achievement of the lowest value of error.

Most ANNs contain some form of "learning rule" which modifies the weights of the connections according to the input patterns that it is presented with. Although there are many different kinds of learning rules used by neural networks, this demonstration is concerned only with one: the delta rule. The delta rule is often utilized by the most common class of ANNs called "backpropagational neural networks" (BPNNs). Backpropagation is an abbreviation for the backwards propagation of error [35]. With the delta rule, as with other types of backpropagation, "learning" is a supervised process that occurs with each cycle or "epoch" (i.e., each time the network is presented with a new input pattern) through a forward activation flow of outputs and the backwards error propagation of weight adjustments [36]. More simply, when a neural network is initially presented with a pattern it makes a random "guess" as to what it might be. It then sees how far its answer was from the actual one and makes an appropriate adjustment to its connection weights. This process can be graphically shown in Figure 9. In this study, Levenberg-Marquardt (LM) algorithm [37] is used as the learning rule. Generally, the LM algorithm needs less time and epochs for convergence, and it performs more efficiently compared to other learning rules, which in turn makes it ideal for training of different networks [37]. The LM algorithm is an approximation of Newton's method, and it is very efficient for training networks which have up to a few hundred weights. In many cases, the Marquardt algorithm was found to converge when other backpropagation techniques diverged [20]. Once a neural network is "trained" to a satisfactory level, it can be used as an analytical tool on other data. In this case, the user no longer specifies any training runs and instead allows the network to work in forward propagation mode only to predict the output as follows.

At first each input value is multiplied by the connected weight value and summed. Then, the result is added to a constant value. This constant value is named bias and is 


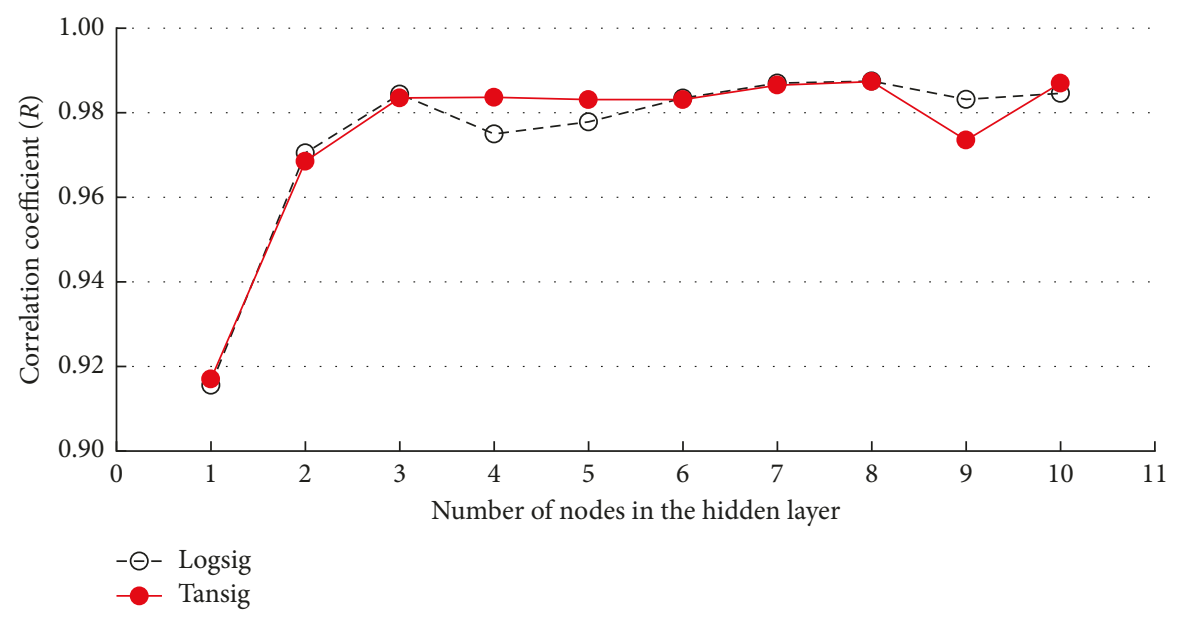

Figure 11: Relation between $R$ and the number of nodes in the hidden layer for different transfer functions.

only connected to nodes in the hidden and output layers. The input into a node can be expressed by (6).

$$
\text { net }_{j}=\sum_{i=1}^{n} w_{i j} x_{i}+\text { bias }_{j} \text {. }
$$

In this equation, net ${ }_{j}$ is the collection of information from each node, $x_{i}$ is the input value, and $w_{i j}$ is the connection weight value. Then, the net ${ }_{j}$ is put through an activation function to produce the output of the neuron. Activation functions which serve to introduce nonlinearity into neural networks include a linear manner as step and rampage functions or nonlinear like Gaussian, sigmoid, hyperbolic tangent functions, and others. The outputs using a logistic activation function can be expressed by (7).

$$
\text { out }_{j}=f\left(\text { net }_{j}\right) \text {. }
$$

In this equation, out ${ }_{j}$ is the output of the $j$ th node and $f$ is the activation function. Figure 10 graphically shows this procedure for a simple ANN network consisting of the input layer consisted of several inputs $\left(X_{1}\right.$ through $\left.X_{n}\right)$, one hidden layer made up of only one node and one output in the output layer. Equation (8) expresses the output of such ANN.

$$
\text { output }=W_{2} \times f\left(W_{1} \times X+b_{1}\right)+b_{2} .
$$

In this expression, $W_{1}$ denotes the input layer weight matrix, $W_{2}$ represents the hidden layer weight value, and $b_{1}$ and $b_{2}$ are the hidden and the output layer bias values, respectively.

6.1. ANN Structure for Predicting the Strength of WFP Connections. In this study, using the finite element results presented in Section 5, one ANN-based model was developed for predicting the strength of the WFP connections. This model consisted of three layers, one input layer, one hidden layer, and one output layer with either LogSigmoid or TanSigmoid transfer functions in the hidden layer and identity (or linear) transfer functions in the output layer. The number of nodes in the input layer was equal to the number of input variables to the ANN model which was equal to the number of effective parameters. These effective parameters are those used in the parametric study presented in Section 5 and are $\alpha_{f}, \alpha_{w}$, and $L_{b} / d_{b}$. As a result, the input layer of the ANN-based model was made up of 3 nodes. The out layer of the ANN-based model consisted of one node. The number of nodes in the hidden layer was determined using a sensitivity analysis. For this purpose, many predicted models were developed by changing the number of neurons or nodes in the hidden layer from one to 10 . Then, the performance of each predicted model was measured using the correlation coefficient, $R$, and compared together to obtain the optimum number of nodes in the hidden layer (all performance measures used in this study are explained in the following section). This comparison for both cases where LogSigmoid or TanSigmoid transfer functions are used in the hidden layer is shown in Figure 11. As Figure 11 indicates, generally by increasing the number of nodes in the hidden layer the accuracy of the predicted models increased. For both LogSigmoid and TanSigmoid transfer functions, the highest performance was achieved for having 8 nodes in the hidden layer. However, as Figure 11 indicates, the difference between the $R$ values corresponding to the ANN-based models of having three and eight nodes in the hidden layer was negligible such that the percentage of difference corresponding to the LogSigmoid and the TanSigmoid transfer functions was $0.3 \%$ and $0.4 \%$, respectively. It should be noted that by increasing the number of nodes in the hidden layer, the number of terms of the mathematical formula of the predicted model increases. It therefore makes the application of such formula difficult for the users. Hence, in this study in order to propose more practical mathematical formulas, one, two, and three nodes were utilized to make up the hidden layer. It is clear that among these three models, the one of three nodes in the hidden layer has the highest accuracy but the lowest applicability.

In this study, performance of the ANN-based models was evaluated using four parameters, including the average absolute percentage error (Err), mean squared error (MSE), mean absolute error (MAE), and correlation coefficient $(R)$. These parameters are given by (9). In these equations, $Y_{i}, T_{i}$, 
$\bar{Y}, \bar{T}$, and $N$ are the predicted output, the actual output obtained from finite element models, the average of the predicted outputs, the average of the actual outputs, and the number of samples, respectively.

$$
\begin{aligned}
\operatorname{Err} & =\frac{1}{N} \sum_{i=1}^{N}\left[\frac{\left|Y_{i}-T_{i}\right|}{T_{i}} \times 100\right], \\
\text { MSE } & =\frac{1}{N} \sum_{i=1}^{N}\left(Y_{i}-T_{i}\right)^{2}, \\
\text { MAE } & =\frac{1}{N} \sum_{i=1}^{N}\left|Y_{i}-T_{i}\right|, \\
R & =\frac{\sum_{i=1}^{N}\left(Y_{i}-\bar{Y}\right)\left(T_{i}-\bar{T}\right)}{\sqrt{\sum_{i=1}^{N}\left(Y_{i}-\bar{Y}\right)^{2} \times \sum_{i=1}^{N}\left(T_{i}-\bar{T}\right)^{2}}} .
\end{aligned}
$$

Overfitting is one of the most common problems during neural network training which potentially can lead to the achievement of a not optimally fitted network. In this case, despite that the error associated to the training data set is a small value, the trained network is not able to adequately predict the target values when new inputs are given to the network. In this study, in order to overcome this problem, the early stopping technique was utilized [38]. In this technique, the total data is divided into three sets: train, validation, and test. In this case, training of the network will be stopped when for the validation data set the network gives the lowest value of error even if further training of the network leads to the lower error with respect to the training data set. In such case, the network is optimally fitted, and the weights and biases at the minimum of the validation error are returned and used to develop the mathematical formulas. This technique is graphically shown in Figure 12. In the present study, $60 \%$ of the total data set which were selected randomly was used for training of the network, $20 \%$ of the total data set was used for validating the network, and the rest of data were utilized for testing. In addition, in order to speed up the learning process and to achieve more reliable ANN-based model, input and output parameters were standardized using (10). In this equation, $X_{\mathrm{std}}, X_{i}, \bar{X}$, and SD are standardized parameter, initial value of the parameter, mean value, and standard deviation of the parameter, respectively.

$$
X_{\text {std }}=\frac{X_{i}-\bar{X}}{\mathrm{SD}}
$$

In this study, a 3-layer network based on the LM/BP learning algorithm with 3 input parameters and 1 hidden layer made up of 1,2 , and 3 neurons were constructed using the neural network toolbox in MATLAB. For instance, the results of the predicted strength values using the ANN method for the training, the validation, and the testing data in the case of having two nodes in the hidden layer with LogSigmoid transfer functions are shown in Figure 13. As Figure 13 indicate for all three sets of data (training, validation, and testing data), the $R$ values are close to unity,

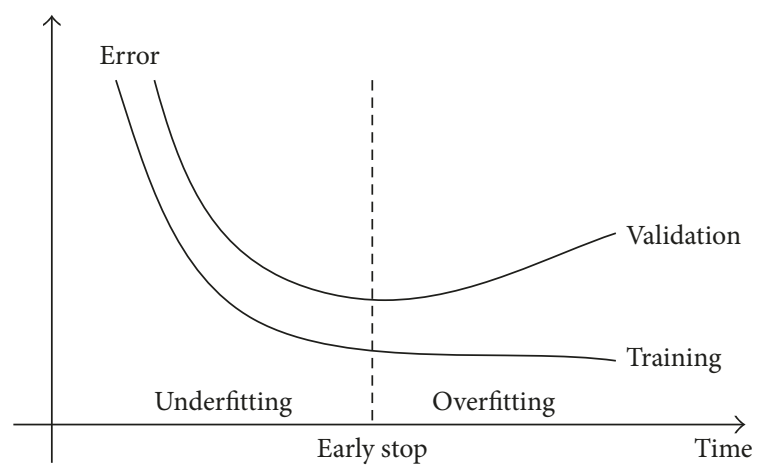

FIgURE 12: Early stop technique to overcome overfitting problem [38].

indicating the high performance of the proposed model. Other performance measures for all other predicted models are summarized in Table 2. As the results presented in Table 2 indicate, all ANN-based models are able to predict the connection strength with an average absolute percentage error less than $6 \%$.

6.2. Investigation of the Adequacy of Sample Size. In addition to the number of nodes in the hidden layer, one factor that can also influence network performance is the quantity of the samples. In this study, the results of 52 finite element models which were analyzed under cyclic loading and 8 experimental models were utilized to make up the sample space. This number of finite element models was obtained by changing the input parameters $\left(\alpha_{f}, \alpha_{w}\right.$, and $\left.L_{b} / d_{b}\right)$ in their reasonable ranges. By considering this fact that the reasonable range of the input parameters is very limited and also running such finite element analysis is very timeconsuming and also due to the limited number of credible experimental tests, the sample size was limited to 60 . It should be noted that, in some cases, this number was within the acceptable range proposed in [39] for sample space used in ANN analyses. In [39], a value of 10 times of the number of degree of freedom is proposed as the minimum size of the sample space. In the present study, by having 3 input variables in the input layer and 1,2, or 3 nodes in the hidden layer, this requirement leads to a sample space of 30,60 , and 90 data, respectively. Hence, it can be concluded that this requirement has been met in the case of using one and two nodes in the hidden layer, but it was not the case when 3 nodes were used in the hidden layer. However, it is worth to mention that the number of data in the sample space can be qualified by investigating the performance of the network. In this study, the performance was evaluated using the coefficient of correlation, $R$. Since for both of the networks having two or three nodes in the hidden layer the $R$ values were greater than 0.95 $(R=0.98(0.97))$ for three (two) nodes in the hidden layer, it was concluded that the number of data in sample space (60) was adequate. This procedure was also adopted by other researchers [40-42] where, due to limitations of the problem under study, the size of sample space was remarkably less than the minimum sample size proposed in [39]. 


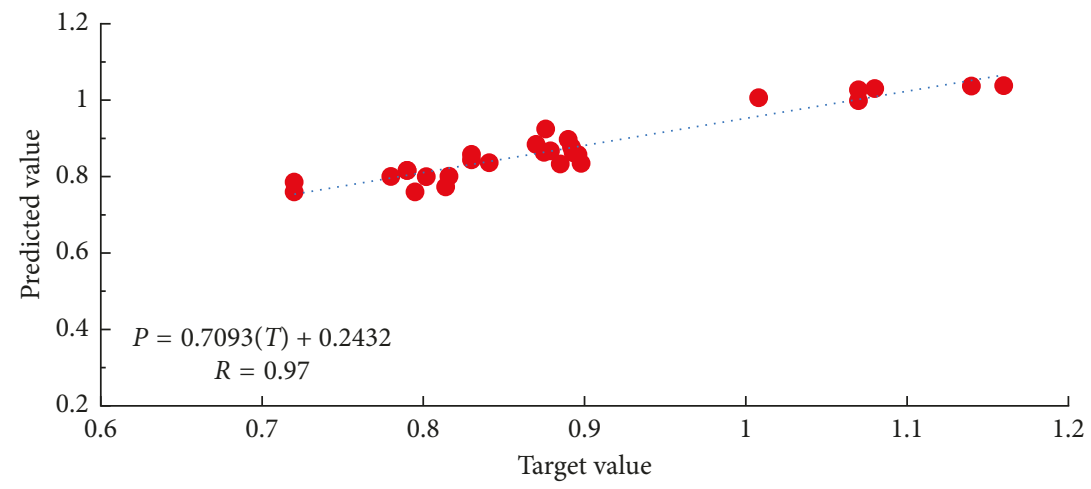

Training data

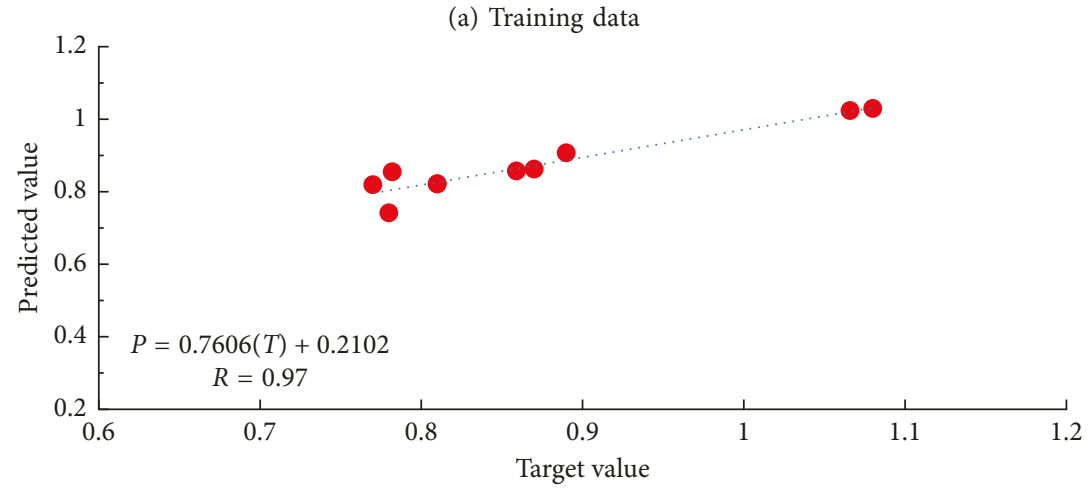

- Validation data

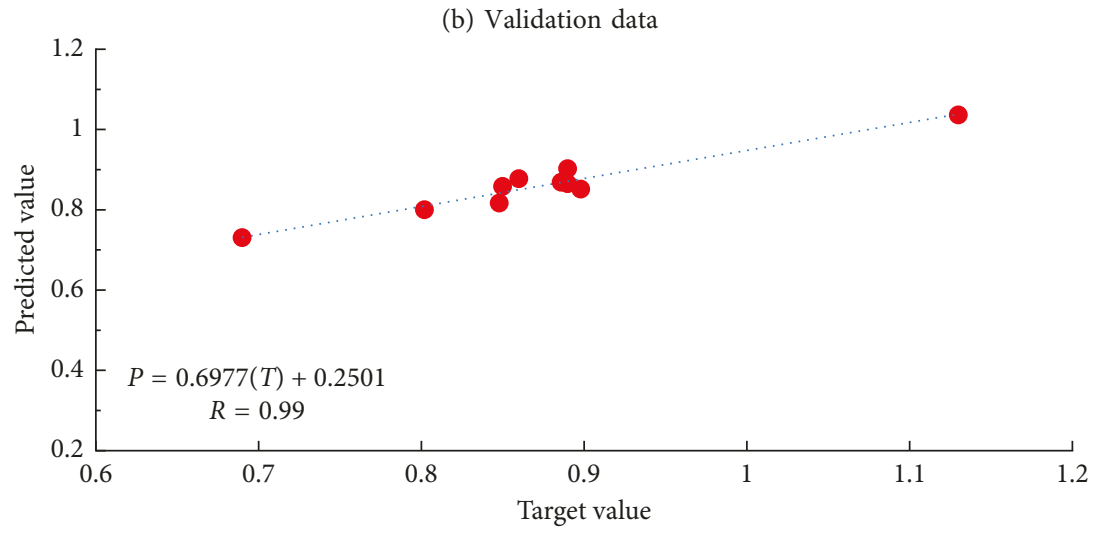

Testing data

(c) Testing data

FIGURE 13: Results of predicted connection strength using ANN model of two nodes in the hidden layer with Logsig transfer function.

TABle 2: Performance statistics for strength's predicted model.

\begin{tabular}{|c|c|c|c|c|c|}
\hline \multirow{2}{*}{ Number of nodes in the hidden layer } & \multirow{2}{*}{ Transfer function } & \multicolumn{4}{|c|}{ Performance measures } \\
\hline & & MSE & MAE & Err\% & $R$ \\
\hline \multirow{2}{*}{ One } & Logsig & 0.0033 & 0.0469 & 5.4 & 0.916 \\
\hline & Tansig & 0.0032 & 0.0460 & 5.3 & 0.917 \\
\hline \multirow{2}{*}{ Two } & Logsig & 0.0018 & 0.0334 & 3.7 & 0.970 \\
\hline & Tansig & 0.0011 & 0.0264 & 3.1 & 0.969 \\
\hline \multirow{2}{*}{ Three } & Logsig & 0.0010 & 0.0248 & 2.9 & 0.984 \\
\hline & Tansig & 0.0010 & 0.0230 & 2.8 & 0.984 \\
\hline
\end{tabular}


Table 3: Constants $C_{1}$ through $C_{16}$.

\begin{tabular}{|c|c|c|c|c|c|c|}
\hline \multirow{2}{*}{$\begin{array}{l}\text { Number of nodes in the hidden layer } \\
\text { Transfer function }\end{array}$} & \multicolumn{2}{|c|}{ One } & \multicolumn{2}{|c|}{ Two } & \multicolumn{2}{|c|}{ Three } \\
\hline & Logsig & Tansig & Logsig & Tansig & Logsig & Tansig \\
\hline $\mathrm{Cl}$ & 0.84 & 0.94 & 1.04 & 0.9 & 0.82 & 0.88 \\
\hline$C 2$ & 0.2 & 0.1 & -0.14 & 0.12 & 0.21 & -0.02 \\
\hline C3 & -48.74 & -28.1 & -0.17 & -0.13 & -0.08 & -0.07 \\
\hline$C 4$ & -3.84 & -1.6 & 61.74 & -14.17 & 0.06 & -0.03 \\
\hline C5 & 2.19 & 1.2 & 8.97 & -0.38 & -38.94 & 80.18 \\
\hline C6 & -3.22 & -2.41 & -0.82 & 2.21 & 0.11 & 20.92 \\
\hline$C 7$ & - & - & -30.94 & -22.01 & 4.19 & -0.28 \\
\hline C8 & - & - & 66.53 & 13.75 & -39.34 & -65.49 \\
\hline C9 & - & - & 2.69 & 1.69 & 61.44 & 37.51 \\
\hline$C 10$ & - & - & -3.05 & -0.18 & 10.83 & 0.70 \\
\hline$C 11$ & - & - & 10.76 & -6.55 & -0.32 & -2.76 \\
\hline $\mathrm{C} 12$ & - & - & - & - & -38.25 & 20.14 \\
\hline$C 13$ & - & - & - & - & -77.27 & 44.12 \\
\hline C14 & - & - & - & - & -4.93 & 1.04 \\
\hline$C 15$ & - & - & - & - & 4.90 & -1.52 \\
\hline C16 & - & - & - & - & -6.77 & -2.89 \\
\hline
\end{tabular}

6.3. ANN-Based Formulations for Predicting the Strength of WFP Connections. Based on the results obtained from the ANNs constructed in the previous section, the ANN-based formulation for predicting the normalized strength of a WFP connection at $4 \%$ total rotation $\left(M / M_{P}\right)$ for different cases, one, two, and three nodes in the hidden layer with Logsig or Tansig transfer function, can be expressed as follows.

Hidden layer made up of one neuron:

$\left(\frac{M}{M_{P}}\right)=C_{1}+\frac{C_{2}}{1+e^{-\beta}}, \quad$ transfer function $=$ Logsig,

$\left(\frac{M}{M_{P}}\right)=C_{1}+C_{2}\left[\frac{2}{1+e^{-2 \beta}}-1\right], \quad$ transfer function $=$ Tansig,

$$
\beta=C_{3} \times \alpha_{f}+C_{4} \times \alpha_{w}+C_{5} \times \frac{L_{b}}{d_{b}}+C_{6} .
$$

Hidden layer made up of two neurons:

$$
\begin{aligned}
\left(\frac{M}{M_{P}}\right)= & C_{1}+\frac{C_{2}}{1+e^{-\beta 1}}+\frac{C_{3}}{1+e^{-\beta 2}}, \text { transfer function }=\text { Logsig, } \\
\left(\frac{M}{M_{P}}\right)= & C_{1}+C_{2}\left[\frac{2}{1+e^{-2 \beta 1}}-1\right] \\
& +C_{3}\left[\frac{2}{1+e^{-2 \beta 2}}-1\right], \quad \text { transfer function }=\text { Tansig, } \\
\beta 1 & =C_{4} \times \alpha_{f}+C_{5} \times \alpha_{w}+C_{6} \times \frac{L_{b}}{d_{b}}+C_{7} \\
\beta 2 & =C_{8} \times \alpha_{f}+C_{9} \times \alpha_{w}+C_{10} \times \frac{L_{b}}{d_{b}}+C_{11} .
\end{aligned}
$$

Hidden layer made up of three neurons:

$$
\begin{aligned}
\left(\frac{M}{M_{P}}\right)= & C_{1}+\frac{C_{2}}{1+e^{-\beta 1}}+\frac{C_{3}}{1+e^{-\beta 2}} \\
& +\frac{C_{4}}{1+e^{-\beta 3}}, \quad \text { transfer function }=\text { Logsig, } \\
\left(\frac{M}{M_{P}}\right)= & C_{1}+C_{2} \times\left[\frac{2}{1+e^{-2 \beta 1}}-1\right]+C_{3} \times\left[\frac{2}{1+e^{-2 \beta 2}}-1\right] \\
& +C_{4} \times\left[\frac{2}{1+e^{-2 \beta 3}}-1\right], \quad \text { transfer function }=\text { Tansig, }
\end{aligned}
$$

$$
\begin{aligned}
& \beta 1=C_{5} \times \alpha_{f}+C_{6} \times \alpha_{w}+C_{7} \times \frac{L_{b}}{d_{b}}+C_{8}, \\
& \beta 1=C_{5} \times \alpha_{f}+C_{6} \times \alpha_{w}+C_{7} \times \frac{L_{b}}{d_{b}}+C_{8}, \\
& \beta 3=C_{13} \times \alpha_{f}+C_{14} \times \alpha_{w}+C_{15} \times \frac{L_{b}}{d_{b}}+C_{16} .
\end{aligned}
$$

In these equations, $M_{P}$ is the beam nominal plastic moment capacity. Constants $C_{1}$ through $C_{16}$ are summarized in Table 3.

6.4. Sensitivity Analysis. At the end of Section 5, several questions were asked. The sixth one was about the most effective parameters that impact on the connection's strength. Here, in order to answer this question, the importance of each input parameter in the ANN-based models is evaluated through a sensitivity analysis using Garson's method [43]. This method was also used by other researchers (e.g., [44, 45]) in different applications. For instance, Figure 14 graphically summarizes the steps of Garson's method for an ANN 


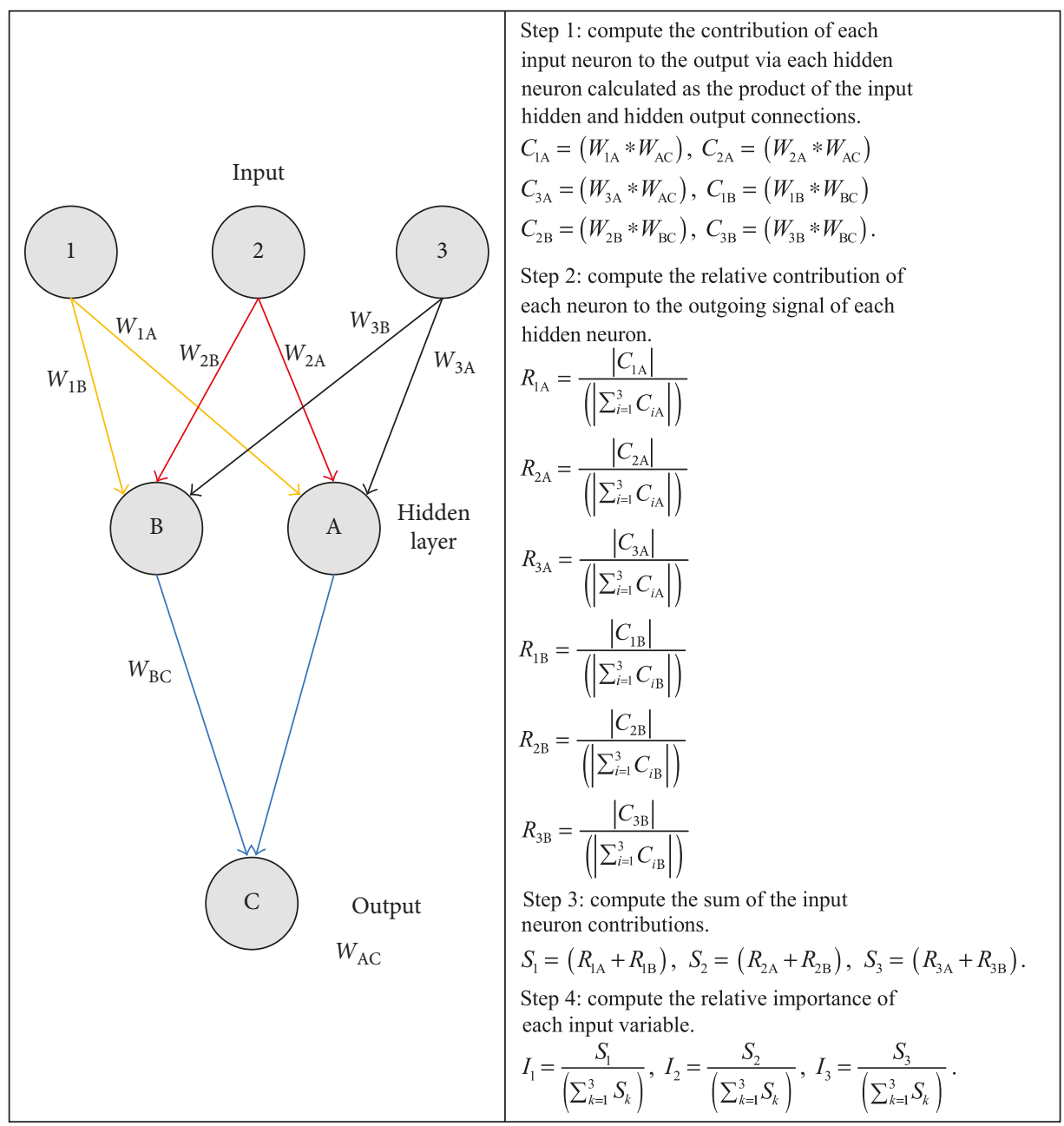

FIGURE 14: Steps of Garson's method [43] for determining the relative importance of input variables.

composed of three inputs with two nodes in its hidden layer. Following this method, the input-hidden and hidden-output weights of the trained ANN models are partitioned, and the absolute values of the weights are taken to calculate the relative importance values [45]. For connection's strength, the importance of each independent parameter (i.e., parameters $\alpha_{f}$, $\alpha_{w}$, and $\left.L_{b} / d_{b}\right)$ was measured and is summarized in Table 4 . As the results of Table 4 indicate, values of the relative importance are remarkably depended on the number of nodes in the hidden layer, while sensitivity to the type of the transfer function is negligible. For any type of the ANN-based models, parameter $L_{b} / d_{b}$ was the most effective parameter, while the less effective parameter, depending on the number of nodes in the hidden layer, was either $\alpha_{f}$ or $\alpha_{w}$.

6.5. Verification of the Proposed ANN-Based Models. In this section, the accuracy of the ANN-based models for predicting the strength of the WFP connections was evaluated using the numerical and available test results presented in Table 1. For instance, Table 5 summarizes the key parameters of the experimentally tested specimens (specimens 53 through 60) along with the average absolute percentage error
TABle 4: Relative importance values for different ANN-based models.

\begin{tabular}{lcccc}
\hline \multirow{2}{*}{$\begin{array}{l}\text { Number of nodes in } \\
\text { the hidden layer }\end{array}$} & $\begin{array}{c}\text { Transfer } \\
\text { function }\end{array}$ & \multicolumn{3}{c}{ Relative importance (\%) } \\
\hline \multirow{2}{*}{ One } & Logsig & 15.1 & $\alpha_{f}$ & $\alpha_{b} / d_{b}$ \\
\multirow{2}{*}{ Two } & Tansig & 16.3 & 9.0 & 73.4 \\
\multirow{2}{*}{ Three } & Logsig & 22.8 & 27.2 & 50.8 \\
& Tansig & 23.3 & 26.7 & 50.0 \\
& Logsig & 17.4 & 21.2 & 61.5 \\
& Tansig & 18.9 & 20.1 & 61.0 \\
\hline
\end{tabular}

obtained using three of the proposed ANN-based models. As the results presented in Table 5 indicate, all of the proposed models were able to adequately predict the connection's strength with the average absolute percentage error (Err) of $15.8 \%, 9.6 \%$, and $9 \%$ for ANN-based models of having one, two, and three nodes in the hidden layer, respectively. However, as it is evident from these results, (22) which is corresponding to the ANN-based models of three nodes in the hidden layer is more reliable than (15) and (19). Furthermore, in order to have a comparison between the accuracy of (22) and the one on basis of the theoretical 
TABle 5: Comparison between test and ANN-based model results in terms of average absolute percentage error.

\begin{tabular}{|c|c|c|c|c|c|c|}
\hline \multirow[t]{2}{*}{ Specimen } & \multirow[t]{2}{*}{$\alpha_{f}$} & \multirow[t]{2}{*}{$\alpha_{w}$} & \multirow[t]{2}{*}{$L_{b} / d_{b}$} & \multicolumn{3}{|c|}{$\begin{array}{l}\text { Number of nodes } \\
\text { in the hidden layer }\end{array}$} \\
\hline & & & & 1 & 2 & 3 \\
\hline FUSD-1 [11] & 0.27 & 2.10 & 11.30 & 27.95 & 19.59 & 17.13 \\
\hline RC06 [12] & 0.33 & 2.21 & 9.07 & 28.50 & 17.46 & 18.43 \\
\hline RC07 [12] & 0.33 & 2.21 & 9.07 & 4.40 & 4.57 & 0.53 \\
\hline $\mathrm{RC08}$ [12] & 0.33 & 2.21 & 9.07 & 21.05 & 10.65 & 12.33 \\
\hline RC2 [13] & 0.27 & 1.36 & 18.52 & 17.14 & 8.28 & 10.48 \\
\hline RC4 [13] & 0.27 & 1.36 & 18.52 & 17.14 & 8.28 & 10.48 \\
\hline LF30 [14] & 0.32 & 1.75 & 13.16 & 6.47 & 2.69 & 1.23 \\
\hline LF50 [14] & 0.32 & 1.75 & 13.16 & 3.85 & 5.57 & 1.54 \\
\hline Average & & & & 15.81 & 9.63 & 9.02 \\
\hline
\end{tabular}

equation (i.e., (4)), the value of connection strength at $4 \%$ total rotation $\left(M / M_{P}\right)$ for all specimens presented in Table 1 was calculated using both equations and results are compared to the related experimental and numerical ones and associated absolute errors are calculated. Figure 7 shows this comparison. As Figure 7 indicates, (22) is more reliable than (4) such that the average of absolute error corresponding to this equation was only $3.74 \%$. It is because of this fact that, as opposed to (22), (4) is not able to take into account the effect of parameter $L_{b} / d_{b}$. Note that, as the results of Section 6.4 indicated, this parameter has a significant effect on the value of connection strength.

\section{Conclusions}

This study was aimed to investigate the effects of the beam flanges and web slenderness and the beam length to the beam overall depth ratio $\left(L_{b} / d_{b}\right)$ on the strength and ductility of the welded flange plate (WFP) connections. The conclusions drawn from this finite element study can be summarized as follows:

(1) Fragility curves obtained on basis of the numerical and the experimental results indicated that the probabilities of achieving adequate strength $\left(M_{\mathrm{cf}} / M_{\mathrm{pb}} \geq 0.8\right)$ and ductility $(\theta \geq 4 \%)$ for a WFP connection are $49 \%$ and $92 \%$, respectively. In other words, for a WFP connection, its strength is of more concern than its ductility.

(2) For a WFP connection, which is used in a special moment frame, limiting the width-to-thickness ratios of the beam flange and web plates to $0.3 \sqrt{E / f_{y}}$ and $2.45 \sqrt{E / f_{y}}$, respectively, may not lead to the achievement of the adequate connection's strength if the beam overall depth is greater than $400 \mathrm{~mm}$.

(3) In WFP connections, when the beam depth is less than $800 \mathrm{~mm}, 0.3$ and 2.2 might be the maximum appropriate values for parameters $\alpha_{f}$ and $\alpha_{w}$, respectively, to achieve the minimum required connection strength requested by AISC [15]. While for deeper beams, 0.275 and 2.2 can be proposed as the maximum allowable values for parameters $\alpha_{f}$ and $\alpha_{w}$, respectively.

(4) Based on the finite element results, when the beam depth is less than $800 \mathrm{~mm}, 0.3$ and 1.9 were the best values for parameters $\alpha_{f}$ and $\alpha_{w}$, respectively, to achieve the highest connection performance. While for deeper beams, 0.275 and 1.9 might be the most suitable values for parameters $\alpha_{f}$ and $\alpha_{w}$, respectively.

(5) The proposed theoretical equation (i.e., (4)) which was based on the theoretical formulations relevant to the flexural strength of beams with noncompact elements was able to adequately predict the connection strength with an average of absolute error of $12.5 \%$. This equation was able only to take into account parameters $\alpha_{f}$ and $\alpha_{w}$.

(6) All six ANN-based models which were developed in terms of the beam length to the beam overall depth ratio and the slenderness ratios of the beam flanges and web plates showed adequate accuracy to predict the strength of the WFP connections at $4 \%$ total rotation. These new formulates can be employed for assessment and design of WFP connections by practical engineers.

(7) Among seven predicting models (six ANN-based models and one theoretical formula), the one on basis of the ANN with three nodes in the hidden layer and with the LogSigmoid transfer function was the most accurate predicting model.

(8) For any type of the ANN-based models, parameter $L_{b} / d_{b}$ was the most effective parameter. Its relative importance, depending on the number of nodes in the hidden layer, was $74 \%, 50 \%$, and $61 \%$ for one, two, and three nodes in the hidden layer, respectively.

(9) The less effective parameter, depending on the number of nodes in the hidden layer, was either $\alpha_{f}$ or $\alpha_{w}$.

(10) The relative importance of parameter $\alpha_{f}$ was $16 \%$, $23 \%$, and $18 \%$ for one, two, and three nodes in the hidden layer, respectively.

(11) The relative importance of parameter $\alpha_{w}$ was $10 \%$, $27 \%$, and $21 \%$ for one, two, and three nodes in the hidden layer, respectively.

\section{Conflicts of Interest}

The authors declare that there are no conflicts of interest regarding the publication of this paper.

\section{References}

[1] S. A. Mahin, "Lessons from damage to steel buildings during the Northridge earthquake," Engineering Structures, vol. 20, no. 4-6, pp. 261-270, 1998. 
[2] D. K. Miller, "Lessons learned from the Northridge earthquake," Engineering Structures, vol. 20, no. 4-6, pp. 249-260, 1998.

[3] K.-H. Lee, Parametric Tests on Unreinforced Connections, SAC Joint Venture, vol. IRichmond, CA, USASAC Joint Venture, 2002 Final Report, SAC/BD-00/01.

[4] A. Hedayat and M. Celikag, "Fracture moment and ductility of welded connections," Proceedings of the ICE-Structures and Buildings, vol. 162, no. 6, pp. 405-418, 2009.

[5] E. P. Popov, T.-S. Yang, and S.-P. Chang, "Design of steel MRF connections before and after 1994 Northridge earthquake," Engineering Structures, vol. 20, no. 12, pp. 1030-1038, 1998.

[6] M. A. Aschheim, "Moment-resistant structure, sustainer and method of resisting episodic loads," 2000. Google Patents.

[7] A. A. Hedayat and M. Celikag, "Post-Northridge connection with modified beam end configuration to enhance strength and ductility," Journal of Constructional Steel Research, vol. 65, no. 7, pp. 1413-1430, 2009.

[8] A. A. Hedayat, H. Saffari, and H. Amid, "Ductility of postNorthridge connections with Angelina beams," Proceedings of the Institution of Civil Engineers-Structures and Buildings, vol. 169, no. 3, pp. 184-209, 2016.

[9] H. Saffari, A. Hedayat, and M. P. Nejad, "Post-Northridge connections with slit dampers to enhance strength and ductility," Journal of Constructional Steel Research, vol. 80, pp. 138-152, 2013.

[10] S. J. Venture, G. D. Committee, and S. J. Venture, Recommended Seismic Design Criteria for New Steel MomentFrame Buildings, Federal Emergency Management Agency, Washington, DC, USA, 2000.

[11] A. Whittaker and A. Gilani, Cyclic Testing of Steel BeamColumn Connections, Earthquake Engineering Research Center, University of California at Berkeley, Berkeley, CA, USA, 1996.

[12] T. Kim, A. S. Whittaker, A. S. J. Gilani, and V. V. Bertero, Cover-Plate and Flange-Plate Reinforced Steel MomentResisting Connections, Pacific Earthquake Engineering Research Center, College of Engineering, University of California, Berkeley, CA, USA, 2000.

[13] M. Ghobadi, A. Mazroi, and M. Ghassemieh, "Cyclic response characteristics of retrofitted moment resisting connections," Journal of Constructional Steel Research, vol. 65, no. 3, pp. 586-598, 2009.

[14] M. Gholami, A. Deylami, and M. Tehranizadeh, "Seismic performance of flange plate connections between steel beams and box columns," Journal of Constructional Steel Research, vol. 84, pp. 36-48, 2013.

[15] A. Seismic, Seismic Provisions for Structural Steel Buildings, (ANSI/AISC 34110), American Institute of Steel Construction, Chicago, IL, USA, 2010.

[16] A. A. Hedayat, H. Saffari, and E. Jazebi, "Investigation of the effective parameters on the strength and ductility of the welded flange plate connections," Asian Journal of Civil Engineering, vol. 17, no. 1, pp. 15-42, 2016.

[17] Y. Pu and E. Mesbahi, "Application of artificial neural networks to evaluation of ultimate strength of steel panels," Engineering Structures, vol. 28, no. 8, pp. 11901196, 2006.

[18] A. Çevik, "A new formulation for longitudinally stiffened webs subjected to patch loading," Journal of Constructional Steel Research, vol. 63, no. 10, pp. 1328-1340, 2007.

[19] S. Gholizadeh, A. Pirmoz, and R. Attarnejad, "Assessment of load carrying capacity of castellated steel beams by neural networks," Journal of Constructional Steel Research, vol. 67, no. 5, pp. 770-779, 2011.

[20] S. Tohidi and Y. Sharifi, "Neural networks for inelastic distortional buckling capacity assessment of steel I-beams," ThinWalled Structures, vol. 94, no. 9, pp. 359-371, 2015.

[21] ANSYS, V. 11.1: User Manual, Ansys Inc., Canonsburg, PA, USA, 2010.

[22] C. S. Gilton and C.-M. Uang, "Cyclic response and design recommendations of weak-axis reduced beam section moment connections," Journal of Structural Engineering, vol. 128, no. 4, pp. 452-463, 2002.

[23] C. Mao, J. Ricles, L.-W. Lu, and J. Fisher, "Effect of local details on ductility of welded moment connections," Journal of Structural Engineering, vol. 127, no. 9, pp. 1036-1044, 2001.

[24] J. M. Ricles, C. Mao, L.-W. Lu, and J. W. Fisher, "Ductile details for welded unreinforced moment connections subject to inelastic cyclic loading," Engineering Structures, vol. 25, no. 5, pp. 667-680, 2003.

[25] A. Specifications, Specification for Structural Steel Buildings, (ANSI/AISC 36010), American Institute of Steel Construction, Chicago, IL, USA, 2010.

[26] J. W. Berman, T. Okazaki, and H. O. Hauksdottir, "Reduced link sections for improving the ductility of eccentrically braced frame link-to-column connections," Journal of Structural Engineering, vol. 136, no. 5, 2009.

[27] S.-H. Chao, K. Khandelwal, and S. El-Tawil, "Ductile web fracture initiation in steel shear links," Journal of Structural Engineering, vol. 132, no. 8, pp. 1192-1200, 2006.

[28] G. Prinz and P. Richards, "Eccentrically braced frame links with reduced web sections," Journal of Constructional Steel Research, vol. 65, no. 10-11, pp. 1971-1978, 2009.

[29] S. J. Venture, "Experimental investigations of beam-column subassemblages," 1996. Rep. No. SAC-96-01, Parts I and II.

[30] FEMA, "State of the art report on connection performance," Rep. No. FEMA355 D, Federal Emergency Management Agency, Washington, DC, USA, 2000.

[31] H. Aslani and E. Miranda, Probabilistic Earthquake Loss Estimation and Loss Disaggregation in Buildings, The John A. Blume Earthquake Engineering Research Center, Stanford University, Stanford, CA, USA, 2005.

[32] H. Aslani and E. Miranda, "Fragility assessment of slabcolumn connections in existing non-ductile reinforced concrete buildings," Journal of Earthquake Engineering, vol. 9, no. 6, pp. 777-804, 2005.

[33] C. M. Ramirez, D. G. Lignos, E. Miranda, and D. Kolios, "Fragility functions for pre-Northridge welded steel momentresisting beam-to-column connections," Engineering Structures, vol. 45, pp. 574-584, 2012.

[34] ANSI/AISC358-10, Prequalified Connections for Special and Intermediate Steel Moment Frames for Seismic Applications, American Institute of Steel Construction, Chicago, IL, USA, 2010.

[35] D. Rumelhart and J. McClelland, Parallel Distributed Processing, MIT Press, Cambridge, MA, USA, 1986.

[36] D. E. Rumelhart, G. E. Hinton, and R. J. Williams, "Learning representations by back-propagating errors," Cognitive Modeling, vol. 5, no. 3, p. 1, 1988.

[37] D. Marquardt, "An algorithm for least squares estimation of non-linear parameters," Journal of the Society for Industrial and Applied Mathematics, vol. 11, no. 2, pp. 431-441, 1963.

[38] R. M. Hristev, The ANN Book, GNU Public License, 1998.

[39] Y. S. Abu-Mostafa, M. Magdon-Ismail, and H.-T. Lin, Learning from Data, Vol. 4, AMLBook New York, New York, NY, USA, 2012. 
[40] F. Tong and X. Liu, "Samples selection for artificial neural network training in preliminary structural design," Tsinghua Science and Technology, vol. 10, no. 2, pp. 233-239, 2005.

[41] Y. Sharifi and S. Tohidi, "Lateral-torsional buckling capacity assessment of web opening steel girders by artificial neural networks-elastic investigation," Frontiers of Structural and Civil Engineering, vol. 8, no. 2, pp. 167-177, 2014.

[42] Y. Sharifi and S. Tohidi, "Ultimate capacity assessment of web plate beams with pitting corrosion subjected to patch loading by artificial neural networks," Advanced Steel Construction, vol. 10, no. 3, pp. 325-350, 2014.

[43] G. D. Garson, "Interpreting neural-network connection weights," AI Expert, vol. 6, pp. 47-51, 1991.

[44] M. M. Abdel Naby, H. W. Leheta, A. A. Banawan, and A. H. Elhewy, "Investigation of various artificial neural networks techniques for the prediction of inland water units' resistance," Ships and Offshore Structures, vol. 3, no. 3, pp. 247-254, 2008.

[45] A. H. Alavi and A.H. Gandomi, "Prediction of principal ground-motion parameters using a hybrid method coupling artificial neural networks and simulated annealing," Computers and Structures, vol. 89, no. 23-24, pp. 2176-2194, 2011. 


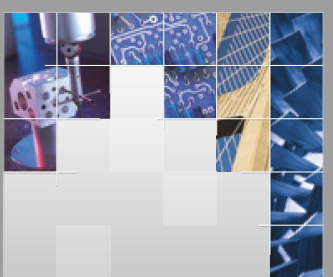

\section{Enfincering}
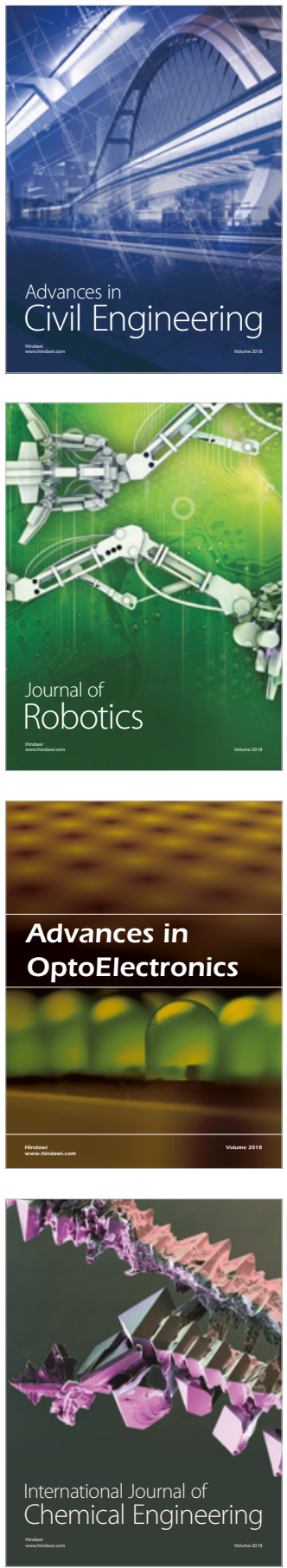

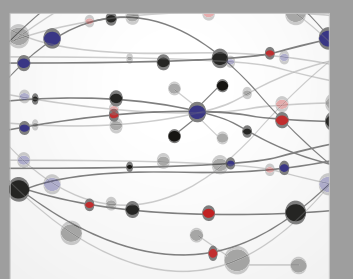

\section{Rotating \\ Machinery}

The Scientific World Journal

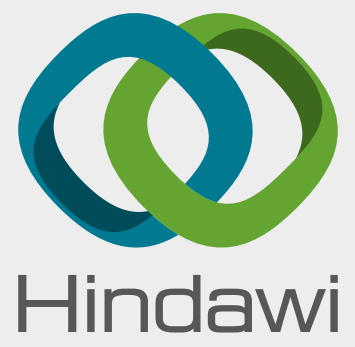

Submit your manuscripts at

www.hindawi.com
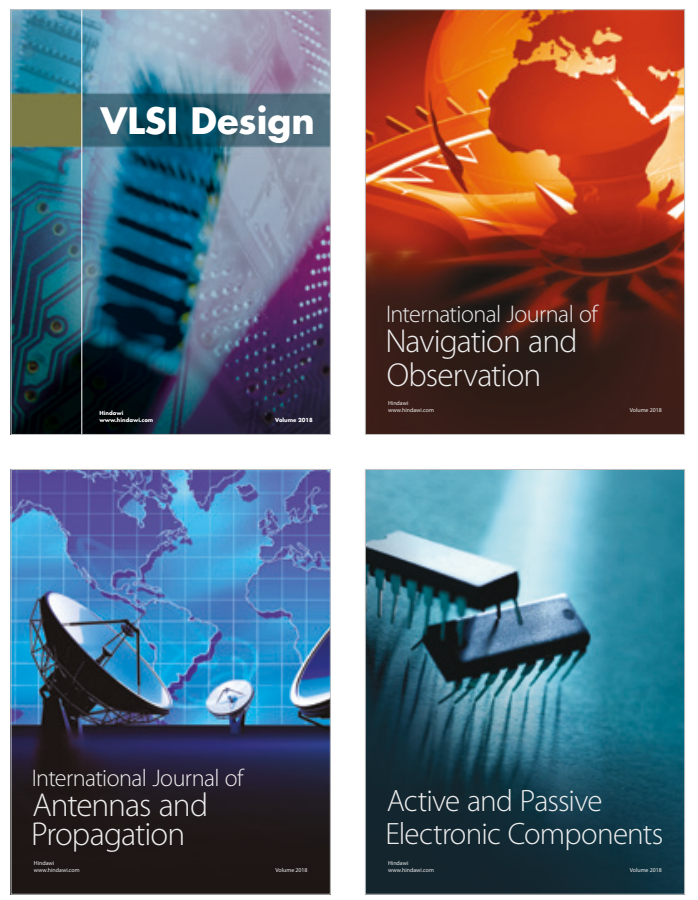
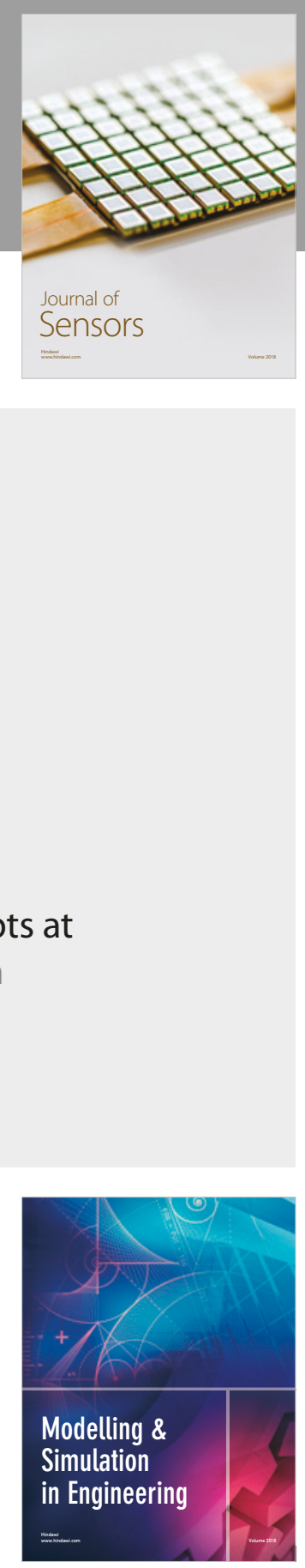

\section{Advances \\ Multimedia}
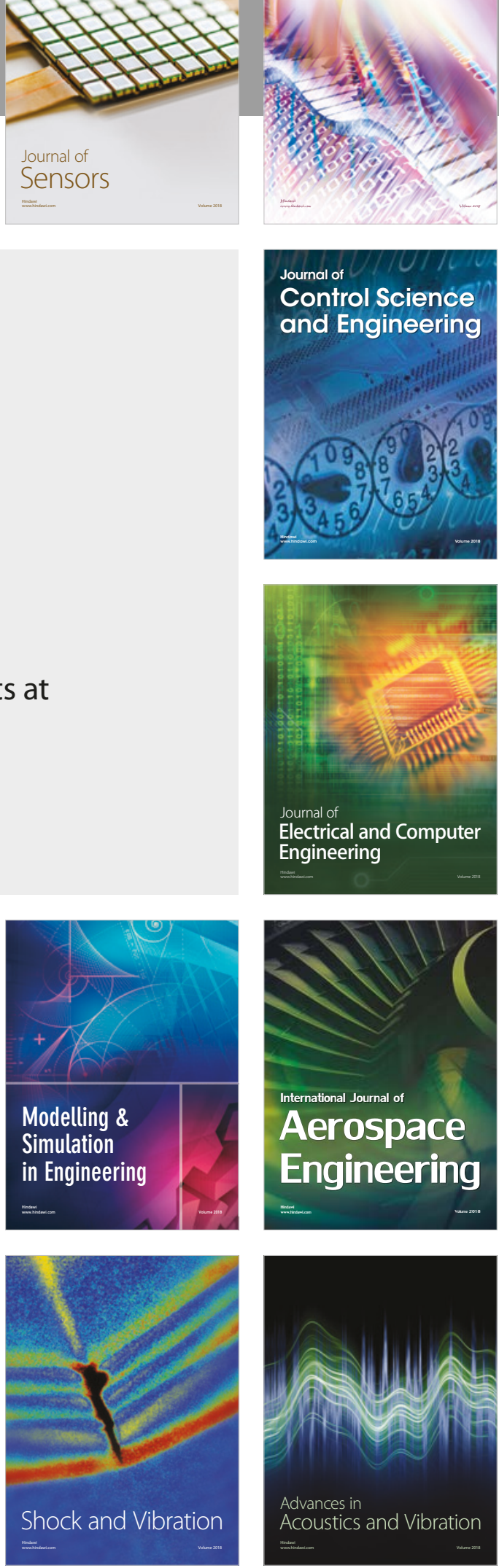